Running Head: Emotional Labor Profiles

\title{
Emotional Labor Profiles: Associations with Key Predictors and Outcomes
}

\author{
Evelyne Fouquereau ${ }^{1 *}$, Alexandre J. S. Morin ${ }^{2}$, Émilie Lapointe ${ }^{3}$, René Mokounkolo ${ }^{1}$, \& Nicolas \\ Gillet $^{1}$ \\ ${ }^{1}$ Université de Tours, France \\ ${ }^{2}$ Concordia University, Canada \\ ${ }^{3}$ University of Nottingham, Ningbo, China
}

Since the first two authors (E.F. \& A.J.S.M.) contributed equally to the preparation of this paper, their order of appearance was determined at random: All should be considered first authors.
* Corresponding author
Evelyne Fouquereau,
Université de Tours,
UFR Arts et Sciences Humaines,
Département de psychologie,
3 rue des Tanneurs, 37041 Tours Cedex 1, France
E-mail: evelyne.fouquereau@univ-tours.fr

Funding: The second author was supported by a grant from the Social Science and Humanity Research Council of Canada (435-2018-0368) in the preparation of this manuscript.

This is the prepublication version of the following manuscript:

Fouquereau, E., Morin, A. J. S., Lapointe, E., Mokounkolo, R., \& Gillet, N. (in press). Emotional labor profiles: Associations with key predictors and outcomes. Work \& Stress. Early view. https://doi.org/10.1080/02678373.2018.1502835

(C) 2018. This paper is not the copy of record and may not exactly replicate the authoritative document published in Work \& Stress.

\begin{abstract}
The present study examines how three emotional labor strategies (hiding feelings, faking emotions, and deep acting) combine within different profiles of workers among two samples characterized by different types and intensity of customer contact. In addition, this research investigates the role of perceived workload as well as perceived organizational support, supervisor support, and colleagues support in the prediction of profile membership. Finally, this research also documents the relation between emotional labor profiles and adaptive and maladaptive work outcomes (job satisfaction, work performance, emotional exhaustion, sleeping problems, psychological detachment, and counterproductive work behaviors). Latent profile analysis revealed three similar emotional labor profiles in both samples. Results also showed the most desirable levels on all outcomes to be associated with Profile 3 (Low Emotional Labor/Low Surface Acting and Moderate Deep Acting), followed by Profile 2 (Moderate Emotional Labor/Moderate Surface Acting and High Deep Acting) and Profile 1 (High Emotional Labor), with most comparisons being statistically significant in both samples. In contrast, a more diversified pattern of findings was observed in the prediction of profile membership. For instance, perceived colleagues support did not predict membership into any of the profiles, while supervisor support predicted an increased likelihood of membership into Profile 3 relative to Profiles 1 and 2.
\end{abstract}

Keywords: emotional labor; deep and surface acting; perceived support; latent profile analyses; work performance; psychological health; customer contact 
Emotional Labor Profiles 2 
In jobs involving contacts with customers, a critical aspect of employees' work performance relates to their ability to display emotions that are consistent with social, occupational, and organizational norms (i.e., to follow display rules; Hochschild, 1983). However, this expectation is generally coupled with the recognition that it is unrealistic to expect employees to systematically experience the required emotions when interacting with customers (Morris \& Feldman, 1996). The concept of emotional labor has been proposed to describe the compensatory strategies used by employees to regulate their emotional expression to meet norms and expectations (Grandey, 2000). Emotional labor strategies take many forms, among which surface acting and deep acting have so far received the greatest amount of scientific attention (Hülsheger \& Schewe, 2011). Whereas deep acting represents attempts at truly feeling the required emotion, surface acting rather involves attempts to simulate (or fake) required emotions or hiding the emotions that one truly feels (Brotheridge \& Lee, 2003; Grandey, 2000). Both strategies can be used in isolation or combination, and are known to require efforts on the part of the employees in order to alter or suppress true emotions (e.g., Goldberg \& Grandey, 2007). Emotional labor is particularly central to some occupations. For example, Gray (2010) demonstrated that emotional labor is a core component of nurses' role in making patients feel safe and comfortable. In other words, emotional labor is an almost invisible bond that the nurse cultivates with the patient.

Despite abundant research on the consequences of emotional regulation (see Hülsheger \& Schewe, 2011, for a meta-analysis), very little is known about how emotional labor strategies combine within specific employees (e.g., Bozionelos \& Kiamou, 2008). Two different approaches can be used to investigate the joint impact of emotional labor strategies. Variable-centered analyses, designed to test how variables relate to other variables, are able to test for interactions effects (i.e., if the effect of a predictor differs as a function of another variable referred to as a moderator). However, these approaches are unable to clearly depict the joint effect of variable combinations involving more than two or three interacting predictors, and become even more complex to interpret when relations display some non-linearity. In contrast, through their focus on the identification of subpopulations of employees characterized by distinct configurations, or profiles, on a set of variables, person-centered analyses are more naturally suited to the consideration of the joint effect of variable combinations without relying on any assumptions (e.g., linearity) in the shape of the interrelations among these variables. The person-centered approach provides a complementary-yet uniquely informative - perspective on these same research questions, focusing on individual profiles rather than specific relations among variables (Marsh, Lüdtke, Trautwein, \& Morin, 2009; Morin \& Wang, 2016). In addition to providing a way to assess how variable-centered expectations would translate to this alternative way of considering the reality, another key advantage of person-centered analyses lies in their ability to identify types of employees which provide a heuristic representation of the data that better match the mindset of managers and practitioners (Morin, Morizot, Boudrias, \& Madore, 2011). In addition, whereas person-centered analyses allow researchers to consider predictors of profile membership, variable-centered analyses do not yet provide a way to study predictors of interaction effects.

Person-centered research has recently started to examine how emotional labor strategies combine within specific individuals (Cheung \& Lun, 2015; Gabriel, Daniels, Diefendorff, \& Greguras, 2015). Still, more research is needed to obtain a clearer picture of the specific emotional labor configurations most frequently occurring in diverse organizational settings. Indeed, a key aspect of the process of construct validation that is required to ascertain that profiles represent substantively meaningful subpopulations is the systematic assessment of the extent to which these profiles generalize to distinct groups of participants (Meyer \& Morin, 2016). More precisely, observing similarity means that generic interventions strategies (designed to select, promote, manage, help or support employees based on their profiles) can be developed and expected to generalize to different types of workers, which is a much more parsimonious approach than having to develop strategies targeting different types of profiles for distinct types of workers.

In this study, we examine the similarity of the emotional labor profiles across two samples of workers characterized by highly differentiated types of contact with the customers and related emotional labor demands. Our first sample includes employees whose work involves direct (i.e., face-to-face interactions), intensive (i.e., emotionally involving), and sustained (i.e., involving mid- to long-term interpersonal relationships) interactions with customers (i.e., teachers, nursing assistants), whereas our second sample includes employees whose work involves very limited or no contacts with customers (i.e., temporary workers doing back office and manual tasks), indirect and sporadic contacts with customers (i.e., phone operators), or direct but sporadic and low-intensity contacts with customers (i.e., check-out assistants). Beyond type of customer contact, each sample was selected to include workers occupying different 
occupations. This enabled us to maximize the generalizability of our results beyond any specific occupational group and to maximize the likelihood that the differences observed between the two samples are attributable to their type of customer contact rather than to any other idiosyncratic characteristic.

This research aims to contribute to our understanding of the combined effects of emotional labor strategies by: (1) identifying employees' profiles strictly defined on the basis of emotional labor strategies, rather than a mixture of indicators conflating emotional labor and other variables (e.g., Cheung \& Lun, 2015); (2) distinguishing among two components of surface acting, namely hiding feelings and faking emotions (Lee \& Brotheridge, 2006); (3) assessing the construct validity of the emotional labor profiles through the consideration of determinants (perceived organizational support, perceived supervisor support, perceived colleagues support, and workload) and outcomes (job satisfaction, emotional exhaustion, sleeping problems, psychological detachment, counterproductive behaviors, and work performance); and (4) systematically assessing the extent to which these configurations and relations can be generalized across two independent samples of employees characterized by distinct types of contacts with customers.

\section{Emotional Labor: Variable-Centered Results}

Main Effects. So far, variable-centered research has shown that surface acting tends to be associated with negative consequences for employees (Hülsheger \& Schewe, 2011), such as emotional exhaustion and cynicism (Lapointe, Morin, Courcy, Boilard, \& Payette, 2011), or with lower levels of job satisfaction and work performance (Huyghebaert et al., 2017). For instance, surface acting was related positively to emotional exhaustion and negatively to job satisfaction among a sample of nurses working in a teaching hospital in Taiwan (Chou, Hecker, \& Martin, 2012). When both surface acting and deep acting are considered, research generally shows that the consequences of surface acting tend to be more severe than those of deep acting (van Gelderen, Konijn, \& Bakker, 2017).

Many theoretical arguments have been offered to account for the adverse consequences of surface acting. Surface acting may lead to feelings of inauthenticity or emotional dissonance as a result of efforts to comply with organizational expectations, thus discouraging employees from reciprocating in the form of positive attitudes and behaviors (Blau, 1964). In addition, surface acting is known to require efforts on the part of employees, which may in the long run contribute to drains one's resources, in turn leading to negative outcomes (e.g., emotional exhaustion, sleeping problems) (Hobfoll, 1989; Hülsheger \& Schewe, 2011). Finally, the various costs associated with surface acting (inauthenticity, dissonance, exhaustion, etc.) may result in lower levels of satisfaction of individuals' basic psychological needs at work, which are themselves known to predict impaired work functioning (Grandey, Rupp, \& Brice, 2015; Huyghebaert et al., 2017).

In contrast, deep acting does not require as much cognitive resources as surface acting (Goldberg \& Grandey, 2007), and does not result in discrepancies between felt and displayed emotions, which have been shown to lead to feelings of inauthenticity (Hülsheger \& Schewe, 2011). Still, despite a general acknowledgement that surface acting is even less desirable than deep acting, empirical findings are mixed regarding the effects of deep acting, which were found to be positive (Huang, Chiaburu, Zhang, Li, \& Grandey, 2015), negative (Cottingham, Erickson, \& Diefendorff, 2015), or simply nonstatistically significant (Hülsheger \& Schewe, 2011).

A Triadic Approach. Although emotional labor has been commonly viewed as comprising two dimensions (surface and deep acting), surface acting itself involves two distinct strategies, hiding one's true feelings and faking the emotions one is expected to display (Brotheridge \& Lee, 2003). Lee and Brotheridge (2011) supported this distinction by demonstrating that organizational rules about the need to suppress negative emotions predicted higher levels of hiding feelings, but not faking emotions. Other studies have revealed well-differentiated relations between these two surface acting components and a variety of antecedents and outcomes (Seger-Guttmann \& Medler-Liraz, 2016). The present research relies on this triadic representation (deep acting, hiding feelings, and faking emotions).

Combined Effects. To date, researchers have primarily focused on how surface and deep acting respectively predict outcomes. However, this approach does not account for the ways in which employees may use surface and deep acting in combination to manage the emotional labor demands that they face on the job. Some workers may heavily rely on both surface and deep acting, whereas others may primarily rely on one strategy or the other. Furthermore, although deep acting is theoretically more beneficial than surface acting, these benefits may not be realized when individuals display high levels of both surface and deep acting (Gabriel et al., 2015). More generally, it seems important to study emotional labor strategies in combination, rather than in isolation to better 
understand the aforementioned mixed results regarding the effects of deep acting. By identifying different types of emotional actors, a person-centered approach would allow researchers to identify how different subpopulations of workers use distinct combinations of surface (faking and hiding emotions) and deep acting strategies to manage their emotions at work. However, the identification of distinct emotional labor profiles is still a relatively under-explored area of emotional labor research.

\section{Emotional Labor: A Person-Centered Approach}

We were able to locate two person-centered studies focusing on the identification of naturally occurring profiles of emotional labor. In the first of these studies, Cheung and Lun (2015) identified three profiles based on the combination of surface acting, deep acting, and the expression of naturally felt emotions. Detailed results are summarized in Table 1, and revealed that the active actors displayed the most positive outcomes, whereas the display rules compliers presented the worst, with the emotionally congruent employees falling in between. In a second study of surface acting and deep acting conducted among two samples of service employees (US and Singapore), Gabriel et al. (2015) identified five profiles. Their results are also summarized in Table 1. In the US sample, negative affectivity predicted a higher likelihood of membership into the regulators and surface actors profiles relative to the nonactors, low actors, and deep actors profiles. The surface actors also presented the highest levels of emotional exhaustion and lowest levels of job satisfaction. Despite many similarities, some of these results differed in the Singapore sample. For instance, in the US sample, job satisfaction was higher for the deep actors relative to the non-actors and low actors. In contrast, in the Singapore sample, job satisfaction was higher for the low actors relative to the non-actors and deep actors.

These findings supported the idea that different profiles of emotional labor can be identified and replicated across cultures. Their results also showed that deep acting tended to be associated with more positive outcomes when it occurred at high levels in combination with low levels of surface acting (deep actors) than when it occurred at high levels in combination with high levels of surface acting (regulators). Moreover, the deep actors did not significantly differ from the non or low actors (low to moderate levels of deep and surface acting) on emotional exhaustion in the US sample. These findings suggest that deep acting is adaptive only when it is accompanied by low levels of surface acting. Indeed, although workers using deep acting may deplete their emotional resources, they also gain additional resources, such as a higher sense of job accomplishment and emotional congruence. Therefore, deep acting may be seen as a job resource (Cheung \& Lun, 2015). More generally, these results potentially explain why prior investigations showed conflicting results (i.e., positive, null, and negative relations) for deep acting (e.g., Hülsheger \& Schewe, 2011).

Despite their interest, both studies (Cheung \& Lun, 2015; Gabriel et al., 2015) failed to consider the distinction between hiding feelings and faking emotions. Rather, they examined surface acting as a unitary construct. In addition, by identifying profiles defined based on an additional variable (i.e., naturally felt emotions), Cheung and Lun's (2015) study made it difficult to isolate the specific effects of emotional labor strategies. Perhaps more importantly, another limitation of these studies is related to their relative neglect of the type of contact that the participants have with customers.

Emotional Labor Profiles and Customer Contact. Whereas some employees have direct (i.e., face-to-face), intensive (i.e., emotionally involving), and sustained (i.e., mid- to long-term) contacts with customers, others only have limited, indirect, and/or sporadic contact with customers, suggesting that emotional demands and emotional labor efforts may vary depending on customer contact type.

Teachers and nursing staff are occupational groups in which interactions with customers (i.e., students and patients, primarily) are direct, intensive, and sustained. A great part of teachers' job takes place in the classroom, in direct contact with their students. Teachers usually interact with the same students for several hours per week, over a school year. In class, teachers have to impart knowledge, maximize student engagement, and minimize student misconduct, all of which are emotionally-laden (Sutton \& Wheatley, 2003). Effective classroom management (e.g., dealing with students' disruptive behavior) represents one of the greatest challenge faced by teachers and has been repeatedly described as emotionally draining (Belt \& Belt, 2017). Furthermore, the emotional demands placed on teachers extend outside the classroom to, for example, interactions with parents (Sutton \& Wheatley, 2003). Thus, a substantial part of teachers' job involves emotionally demanding work (Hargreaves, 1998).

Similarly, nursing staff interact directly with patients, often on an ongoing basis. For example, nurses and nurse assistants play a role in patients' admission to the hospital, in monitoring patients' condition during hospitalization, in administering treatment or in performing routine activities (e.g., 
bathing; Gray, 2010). Illustrating the importance of that bond with patients, research in the field of nursing refers to that bond as a nurse-patient relationship (Henderson, 2001). This relationship is seen a central job component and as requiring substantial commitment, dedication, and emotional engagement (Gray, 2010; Henderson, 2001). Emotional labor is also seen as central, particularly given the physical, emotional, and/or cognitive vulnerability of patients (Gray, 2010; Henderson, 2001).

Furthermore, teachers and nursing staff accomplish their duties in a context were resources might already be depleted by additional work-related stressors. Research has identified, among others, time pressure, educational reforms, and increased number of students as major sources of stress for teachers (e.g., Skaalvik \& Skaalvik, 2010). Similarly, nursing is characterized by unpredictability, increasing nurses-to-patient ratio, poor interpersonal relationships with doctors, and continuous confrontation with a broad range of diseases, injuries, and traumatic events (e.g., McVicar, 2016). Not surprisingly given connections between work-related stress and burnout, these types of occupations are known to present fairly high rates of burnout (e.g., Adriaenssens, De Gucht, \& Maes, 2016).

In contrast, many other types of employees usually have no or very limited contacts with customers, leading them to face limited emotional demands at work (Brotheridge \& Grandey, 2002). That would be the case for temporary workers working in the back office of a fulfillment center and performing mostly manual tasks (e.g., sorting items and loading packages in delivery vehicles). Moreover, indirect and shortterm contacts with customers, such as those characterizing the work of phone operators, require more limited and sporadic emotional efforts when compared to job involving sustained interactions with the customers (Mann, 2004). Phone operators work in call centers, and thus are dealing with customers, but only have to do so indirectly (i.e., on the phone rather than face-to-face) and for limited periods of time (i.e., the duration of a phone call). Because they are not physically in the presence of customers, phone operators also have more opportunities for implementing 'back stage coping strategies' (i.e., adopting a friendly tone of voice but rolling eyes at colleagues; Mann, 2004), which likely limit their emotional regulation burden to verbal cues. Finally, employees with direct yet sporadic low-intensity contacts with customers should also experience more limited emotional demands when compared to nurse assistants and teachers (Mann, 2004). That would be the case for check-out assistants, who are responsible of handling payments from customers where they leave a shop.

Because the nature of the contacts that they have with customers is more time-limited, sporadic, indirect, and typically not as intensive, emotional labor appears to be less central for these groups of employees (i.e., temporary workers, phone operators, and check-out assistants), than among teachers and nursing staff. This logic is consistent with Brotheridge and Grandey (2002) suggestion that employees who do not hold customer-facing jobs seldom need to perform emotional labor. They also demonstrated that, although customer service workers (e.g., sales clerks) and human service workers (e.g., nurses) both perform work involving customer contact, the emotional demands experienced by customer service workers were much lower than those experienced by human service workers. The distinction we make in terms of customer contact in this study also echoes early work by Hochschild (1983), who suggested that jobs high in emotional labor involve, in terms of duration, intensity and frequency, large amounts of customer contact. Differences in customer contact type raise the possibility that teachers and nursing staff rely on different combinations of emotional labor strategies to cope with job requirements, when compared to other employees (i.e., temporary workers, phone operators, and check-out assistants). In the present research, we consider possible differences in the nature of the emotional labor profiles, as well as their antecedents and outcomes, as a function of these two groups of employees (teachers/nurse assistants vs. temporary workers, phone operators, and check-out assistants). However, in the absence of prior studies on emotional labor profiles among different types of workers, we leave as an open question whether the profiles would differ between these two samples.

\section{Determinants of Emotional Labor Profiles}

Despite the fact that Gabriel et al. (2015) considered a relatively wide range of predictors of emotional labor profiles, the role of additional possibly important predictors of these profiles have yet to be systematically investigated. More specifically, we consider the role of perceived organizational, supervisor, and colleagues support, as well as workload in the prediction of profile membership, based on the fact that both surface and deep acting tend to be influenced by these factors, as outlined below.

Grandey (2000) argued that job demands such as workload are situational cues for the emotion regulation process. Higher workloads may generate negative emotions, leading to a discrepancy between felt emotions and organizational display rules (Mesmer-Magnus, DeChurch, \& Wax, 2012). Such a 
discrepancy would signal to workers that they must regulate their emotions and/or emotional expressions through surface and deep acting. Rupp and Spencer (2006) noted that exposure to higher job demands was associated with the need to expand more efforts to regulate one's emotions, which may lead employees to rely on the less resource-costly deep acting strategy (Chou et al., 2012; Tuxford \& Bradley, 2015). Surface acting means that ones' emotions need to be constantly monitored to ensure that facial expressions and other verbal and nonverbal cues remain adequate irrespective of whether they reflect or not true feelings. Compared to deep acting, this process requires considerable mental efforts (Goldberg \& Grandey, 2007).

In addition to job demands, emotional labor seems to be influenced by the amount and quality of job resources on which employees can draw when they experience negative emotions. Among the variety of job resources that can play a role in emotional regulation, employees' perceptions of the social support received from their organization, supervisor, and colleagues appear to be particularly important to consider. Perceived organizational support refers to employees' perceptions of the extent to which their organization cares about their well-being and values their contributions (Eisenberger, Huntington, Hutchison, \& Sowa, 1986). Organizational support theory has been extended to perceived supervisor support and perceived colleagues support (i.e., employees' perceptions of the extent to which their supervisor or colleagues care about their well-being and value their contributions) (Eisenberger \& Stinglhamber, 2011). Experiencing caring and respect from the organization, supervisor, and colleagues is likely to fulfill employees' basic needs for emotional support, thus creating a sense of belonging and indebtedness, which may in turn lead to positive work outcomes (Eisenberger \& Stinglhamber, 2011). Support from the organization, supervisor, and colleagues should thus create a positive working environment, which may even reduce the need to rely on emotional labor (Grandey, 2000). Indeed, employees who feel supported at work may genuinely feel the emotions that are expected by their organization, and may come to internalize a genuine desire to help their organization (Mishra, 2014). With few exceptions (Yoo \& Arnold, 2016), research has generally shown that social support was positively linked to deep acting but negatively related or unrelated (e.g., Hur, Han, Yoo, \& Moon, 2015) to surface acting. For instance, Chou et al. (2012) demonstrated that nurses' perceived organizational support was positively related to deep acting and negatively to surface acting. Tuxford and Bradley (2015) also showed that teachers' perceived social support from their supervisor and colleagues was negatively linked to surface acting.

The Present Research

In the present study, we examine how hiding feelings, faking emotions, and deep acting combine within different profiles of workers across two independent samples of employees from occupations characterized by different types of contacts with customers. To our knowledge, this study represents the first attempt to do so while a single person-centered study has similarly looked at the combination between surface and deep acting in the estimation of employees' emotional labor profiles (Gabriel et al., 2015). We expect similar profiles to be identified (e.g., a profile characterized by very low levels of deep and surface acting, a profile characterized by high levels of deep acting and low levels of surface acting, a profile characterized by high levels of deep and surface acting), although we allow for variations based on our separate consideration of the hiding feelings and faking emotions components of surface acting.

We also extend previous research by examining predictors of profile membership related to job demands (workload) and resources (perceived organizational, supervisor, and colleagues support). Based on the aforementioned variable-centered results regarding the relations between these predictors and emotional labor, we first expect perceived workload to predict a higher likelihood of membership into the regulators (high levels of deep and surface acting) profile relative to the non-actors (very low levels of deep and surface acting) and low actors (low to moderate levels of deep and surface acting) profiles. We also hypothesized perceived workload to predict a higher likelihood of membership into the surface actors profile (low levels of deep acting combined with high levels of surface acting) relative to the regulators and deep actors (low levels of surface acting combined with high levels of deep acting) profiles. In addition, we hypothesized that perceived organizational, supervisor, and colleagues support will predict a higher likelihood of membership into the deep actors profile relative to the profiles characterized by lower levels of deep acting (non-actors, low actors, and surface actors profiles). In the absence of consistent findings on the effects of perceived social support on surface acting, we leave as an open question whether these three sources of social support would differentially relate to the profiles.

Associations between profile membership and work outcomes will also be estimated to extend Gabriel et al.'s (2015) study which considered emotional exhaustion, job satisfaction, and inauthenticity. We rely on a complementary set of outcomes related to participants' attitudes (job satisfaction and psychological 
detachment), behaviors (work performance and counterproductive behaviors), physical health (sleeping problems), and psychological health (emotional exhaustion). These outcomes were retained based on the previously reported evidence showing that they all present differentiated relations with employees' levels of surface and deep acting (e.g., Hülsheger \& Schewe, 2011). For instance, numerous variable-centered studies showed that, contrary to surface acting, deep acting was positively related to job satisfaction (e.g., Chou et al., 2012). van Gelderen et al. (2017) also demonstrated that surface acting and deep acting were respectively negatively and positively related to employees' levels of work performance. Finally, Seger-Guttmann and Medler-Liraz (2016) found that hiding feelings was more strongly and negatively related to satisfaction than faking emotions. Based on the research reviewed previously, we expect profiles of employees mainly characterized by high levels of surface acting (the surface actors profile) to present the worst outcomes. Based on the inconsistent findings on the outcomes associated with the nonactors and low actors profiles, we leave as an open question the standing of these two profiles relative to that of the deep actors and regulators profiles. We also expect that a profile characterized by high levels of hiding feelings would be associated with more negative outcomes (e.g., lower job satisfaction) than a profile characterized by high levels of faking emotions (Seger-Guttmann \& Medler-Liraz, 2016).

Finally, relying on a framework proposed by Morin, Meyer, Creusier and Biétry (2016) to guide tests of profile similarity across samples, we assess the extent to which the profiles and their relations with predictors and outcomes differ across samples of employees occupying positions characterized by direct, intensive, and sustained vs. limited, indirect, and/or sporadic contact with customers. In the absence of prior empirical or theoretical guidance, we leave as an open research question the extent to which the profiles, as well as their relations with predictors and outcomes, will be similar or different across these two samples.

\section{Participants and Procedure}

\section{Method}

Sample 1. This sample includes a total of 331 participants (87 men and 244 women) occupying a position involving direct, intensive, and sustained contact with customers, including 236 teachers and 95 nursing assistants. These participants were recruited in various organizations located in France, and completed a paper-and-pencil questionnaire administered by research assistants. In each organization, participants received a survey packet including the questionnaire, a cover letter explaining the study's purposes, and a consent form in which the anonymous and voluntary nature of their participation was emphasized. Most participants (93.7\%) were employed in the public sector and worked full time $(86.4 \%)$ on a permanent basis $(96.4 \%)$. Respondents were aged between 21 and 59 years $(M=38.99$, $S D=9.22)$ and had an average organizational tenure of 9.42 years $(S D=8.58)$.

Sample 2. This sample includes 311 participants ( 82 men; 229 women) occupying a position involving limited, indirect, and/or sporadic contact with customers, including 114 temporary workers from an employment agency with very limited or no contacts with customers, 103 telephone operators working in call centers with indirect and sporadic contacts with customers, and 94 check-out assistants with direct, but low-intensity sporadic contacts with customers. The temporary workers worked for an electronic commerce company in a fulfillment center located in France. They occupied a variety of positions, all involving no direct contact with the customers (including packing items into a bin, picking up completed order forms, packing these orders, sorting items, and placing packages in delivery vehicles). These participants were recruited from organizations located in France, and completed a paper-and-pencil questionnaire following the same procedures as for Sample 1. All were employed in the private sector, were aged between 18 and 56 years $(M=28.54, S D=8.27)$, had an average organizational tenure of 4.77 years $(S D=5.47)$, and $67.2 \%$ of them worked full-time.

\section{Measures}

Emotional Labor (Profile Indicators). Hiding feelings ( 3 items, $\alpha$ s $=.89$ in Sample 1 and .91 in Sample 2; e.g., "Hide my true feelings about a situation"), faking emotions ( 3 items, $\alpha=.88$ in Sample 1 and .90 in Sample 2; e.g., "Showing emotions that I don't feel"), and deep acting (3 items, as $=.85$ in Sample 1 and .86 in Sample 2; e.g., "Make an effort to actually feel the emotions that I need to display to others") were assessed with the revised version of Brotheridge and Lee's (2003) Emotional Labor Scale (Lee \& Brotheridge, 2006). Participants were asked to rate how frequently they performed each listed behavior in a typical work day using a 5-point scale ranging from 1 (never) to 5 (always).

Perceived Organizational Support (Predictor). Perceived organizational support was assessed using the four items $(\alpha$ s $=.72$ in Sample 1 and .81 in Sample 2; e.g., "My organization really cares about my well-being”) short version (Caesens, Stinglhamber, \& Luypaert, 2014) of Eisenberger et 
al.'s (1986) Survey of Perceived Organizational Support (SPOS). Each of these items were rated on a 7-point Likert-type scale ranging from "Strongly Disagree" to "Strongly Agree".

Perceived Supervisor Support (Predictor). Perceived supervisor support was assessed using the same four items ( $\alpha$ s $=.84$ in Samples 1 and 2; e.g., "My supervisor cares about my general satisfaction at work") adapted from the SPOS (Eisenberger et al., 1986). Following prior studies (e.g., Caesens et al., 2014), these items were adapted by replacing the word "organization" with the term "supervisor", and were rated using the same 7-point response scale.

Perceived Colleagues Support (Predictor). Perceived colleagues support was assessed using the same four items ( $\alpha \mathrm{s}=.79$ in Sample 1 and .77 in Sample 2; e.g., "My colleagues really care about my well-being") adapted from the SPOS (Eisenberger et al., 1986). Following prior studies (e.g., Caesens et al., 2014), these items were adapted by replacing the word "organization" with the term "colleagues", and were rated using the same 7-point response scale.

Perceived Workload (Predictor). Spector and Jex's (1998) five-item Quantitative Workload Inventory was used to measure perceived workload ( $\alpha$ s $=.82$ in Sample 1 and .84 in Sample 2; e.g., "How often does your job require you to work very hard?"). Responses were provided on a 5-point scale ranging from 1 (never) to 5 (always).

Job Satisfaction (Outcome). A single item measure (Shimazu, Schaufeli, Kamiyama, \& Kawakami, 2015) was used to ask workers to indicate "Overall, to what extent are you satisfied with your job". Responses were provided on a 4-point scale (1- unsatisfied to 4- totally satisfied).

Work Performance (Outcome). Performance was assessed with a single item developed by Kessler et al. (2003), and asking workers to indicate "On a scale ranging from 1 to 10, how would you rate you work performance over the past four weeks (with 0 reflecting the worst work performance anyone could have and 10 the performance of a top worker?)".

Emotional Exhaustion (Outcome). Emotional exhaustion was assessed with the relevant five-item subscale ( $\alpha$ s $=.84$ in Sample 1 and .90 in Sample 2; e.g., "I feel emotionally drained by my work") from the Maslach Burnout Inventory-General Survey (Schaufeli, Leiter, Maslach, \& Jackson, 1996). All items were rated on a 1 (strongly disagree) to 5 (strongly agree) response scale.

Sleeping Problems (Outcome). We used the four items ( $\alpha \mathrm{s}=.87$ in Sample 1 and .89 in Sample 2) developed by Jenkins, Stanton, Niemcryk, and Rose (1988) to measure sleeping problems during the last month. Each item (i.e., "difficulty falling asleep", "difficulty staying asleep", "waking up several times per night", and "waking up feeling tired and worn out after the usual amount of sleep") was rated on a 6-point scale: not at all (1), 1 to 3 days (2), 4 to 7 days (3), 8 to 14 days (4), 15 to 21 days (5), and 22 to 31 days (6).

Psychological Detachment (Outcome). Psychological detachment was assessed with a four-item scale ( $\alpha$ s $=.93$ in Sample 1 and .90 in Sample 2; e.g., "I forget about work") developed by Sonnentag and Fritz (2007). Following a common stem ("In the evening, after work, and when I am on a weekend/vacation"), items were rated on a 5-point scale ranging from 1 (totally disagree) to 5 (totally agree).

Counterproductive Work Behaviors (Outcome). Five items focusing on social interactions ( $\alpha \mathrm{s}=.57$ in Sample 1 and .69 in Sample 2; e.g., "Insulted someone about their job performance") (Spector, Bauer, \& Fox, 2010) were used to assess counterproductive work behaviors. Responses were provided on a 5 -point frequency scale, ranging from 1 (never) to 5 (every day).

\section{Preliminary Analyses}

Analyses

Preliminary factor analyses were conducted using Mplus 8 (Muthén \& Muthén, 2017) to verify the psychometric properties of all measures. Factor scores were saved from these measurement models and used as inputs for the main analyses (for details on the advantages of factor scores, see Meyer \& Morin, 2016; Morin, Meyer et al., 2016). Details on these preliminary measurement models, their invariance, and composite reliability $(\omega=.701$ to .917$)$ are provided in online supplements available at [link to be provided upon acceptation for blind review purposes]. Correlations among all factor scores and observed variables are reported in Table 2. To ensure that the measures remained comparable across samples, these factors scores (estimated with a $S D$ of 1 , and a grand mean of 0 across samples) were saved from invariant (loadings, intercepts, uniquenesses, and latent variance-covariance) measurement models (Millsap, 2011). These analyses revealed latent mean differences across samples showing that participants from Sample 2 tended to present higher scores on the deep acting (.601 SD units higher than in Sample 1) and psychological detachment (.632 SD units higher than in Sample 1) factors, but lower scores on the perceived workload factor (.676 SD units lower than in Sample 1). 
Factor scores do not explicitly control for measurement errors the way latent variables do, however they provide a partial control for measurement errors by giving more weight to more reliable items (Skrondal \& Laake, 2001), and preserve the underlying nature of the measurement model (e.g., measurement invariance) better than scale scores (Morin, Meyer et al., 2016).

\section{Latent Profile Analyses (LPA)}

Models were estimated using Mplus 8 (Muthén \& Muthén, 2017) robust maximum likelihood estimator (MLR) and Full Information Maximum Likelihood (FIML; Enders, 2010) to handle missing data (0\% in Sample 1; 0 to $3.54 \%$ in Sample 2). All LPA were conducted using 5000 random sets of start values, 1000 iterations, and retained the 200 best solutions for final stage optimization (Hipp \& Bauer, 2006). LPA models including 1 to 8 profiles were first estimated separately in each sample using the three emotional labor factors as profile indicators to see whether the same number of profiles would be extracted in each sample. To determine the optimal number of profiles in the data, multiple sources of information need to be considered, including the examination of the substantive meaningfulness, theoretical conformity, and statistical adequacy of the solutions (Marsh et al., 2009). Once the optimal number of profiles was selected in each sample, these two solutions were integrated into a single multi-group LPA model allowing for systematic tests of profile similarity. These tests followed the strategy proposed by Morin, Meyer et al. (2016) and was extended to tests of predictive and explanatory similarity once predictors and outcomes were included in the model. Additional technical details on LPA estimation and model selection are reported in the online supplements.

\section{Predictors and Outcomes of Profile Membership}

Multinomial logistic regressions were used to test the relations between the predictors (perceived organizational support, perceived supervisor support, perceived colleagues support, and workload) and the likelihood of profile membership. Because demographic characteristics are known to be at least weakly associated with workers' level of reliance on different emotional labor strategies (Simpson \& Stroh, 2004), these analyses where conducted while controlling for sex and age (although results remained unchanged by the inclusion of these controls). Two alternative models were contrasted. First, relations between predictors and profile membership were freely estimated across samples. Second, the predictive similarity of the model was tested by constraining predictions to equality across samples.

Outcomes were also incorporated into the final solution. In these analyses, outcome measures (emotional exhaustion, sleeping problems, psychological detachment, counterproductive work behaviors, job satisfaction, and work performance) were first specified to be freely associated with profile membership in each sample. We then proceeded to tests of explanatory similarity by constraining the within-profile means of these outcomes to equality across samples. We used the MODEL CONSTRAINT command of Mplus to systematically test mean-level differences across pairs of profiles using the multivariate delta method (Raykov \& Marcoulides, 2004).

A strong assumption of LPA with predictors or outcomes is that the nature of the profiles should remain unaffected by the inclusion of covariates (Diallo, Morin, \& Lu, 2017; Marsh et al., 2009; Morin, Morizot et al., 2011). To ensure that this did not happen, the solution to which predictors and outcomes were included was defined using the exact parameter estimates (rather than random start values) from the final unconditional model (i.e., the final solution retained before including the covariates) (Morin, 2016).

\section{Latent Profile Solution}

\section{Results}

The detailed results and rationales used in the selection of the most optimal solution are reported in the online supplements. These results supported the decision to retain the 3-profile solution in each sample, and generally supported the similarity of these profiles across samples, while also showing that deep acting levels tended to be higher in two of the profiles in Sample 2. These results also demonstrated that the relative sizes of these profiles differed across samples. The final LPA solution retained in this study is illustrated and summarized in Figure 1. Profile 1 was identical in both samples, and characterized employees relying on a high level of all emotional labor strategies. This High Emotional Labor characterized $16.08 \%$ of Sample 1 relative to $28.13 \%$ of Sample 2. Across samples, Profile 2 displayed moderate levels on all emotional labor strategies. However, whereas the observed levels of emotional labor are similar across all three strategies in Sample 1, levels of deep acting are much higher than the levels of hiding feelings and faking emotions in Sample 2. For this reason, this profile was labelled Moderate Emotional Labor in Sample 1 where it characterized 46.92\% of the participants, and Moderate Surface Acting and High Deep Acting in Sample 2 where it 
characterized $29.65 \%$ of the participants. Finally, Profile 3 presented low to moderately low levels on all emotional labor strategies, although levels of deep acting were higher than levels of hiding feelings and faking emotions in Sample 2. For this reason, this profile was labelled Low Emotional Labor in Sample 1 where it characterized 37.04\% of the participants, and Low Surface Acting and Moderately Low Deep Acting in Sample 2 where it characterized $42.22 \%$ of the participants. This solution resulted in a high level of classification accuracy, as shown by an entropy of .906 , average probabilities of membership in the dominant profile from .895 to .963 , and low cross-probabilities from 0 to .068 (detailed parameter estimates are available in Table S6 and S7 of the online supplements).

\section{Predictors}

The results from the analyses involving predictors (see the online supplements for additional details) revealed that the effects of these predictors on profile membership generalized across samples, despite the differences related to the levels of deep acting in two of the profiles. This observation supports the idea that Profiles 2 and 3 tap into similar psychological processes across samples. Results from the multinomial logistic regressions estimated in the model of predictive similarity are reported in Table 3. These results showed that age was unrelated to profile membership, whereas females were two times more likely than males to be members of Profile 1 (High Emotional Labor) relative to Profiles 2 (Moderate Emotional Labor/Moderate Surface Acting and High Deep Acting) and 3 (Low Emotional Labor/Low Surface Acting and Moderately Low Deep Acting). In addition, whereas employee perceptions of colleagues support did not predict membership into any of the profiles, their perceptions of the support received from their supervisors predicted an increased likelihood of membership into Profile 3 (Low Emotional Labor/Low Surface Acting and Moderately Low Deep Acting) relative to Profiles 1 (High Emotional Labor) and 2 (Moderate Emotional Labor/Moderate Surface Acting and High Deep Acting). In contrast, workload perceptions predicted an increased likelihood of membership into Profiles 1 (High Emotional Labor) and 2 (Moderate Emotional Labor/Moderate Surface Acting and High Deep Acting), relative to Profile 3 (Low Emotional Labor/Low Surface Acting and Moderately Low Deep Acting). Finally, employee perceptions of the support received from their organization predicted an increased likelihood of membership into Profile 2 (Moderate Emotional Labor/Moderate Surface Acting and High Deep Acting) relative to Profile 1 (High Emotional Labor).

\section{Outcomes}

The results from the analyses involving outcomes (see the online supplements for additional details) revealed that the effects of profile membership on these outcomes differed across samples. Outcome levels observed in each profile within each sample are reported in Table 4. These results are very consistent across outcomes, showing the most desirable levels on all outcomes (i.e., higher levels of job satisfaction, work performance and psychological detachment, and lower levels emotional exhaustion, sleeping problems, and counterproductive work behaviors) to be associated with Profile 3 (Low Emotional Labor/Low Surface Acting and Moderately Low Deep Acting), followed by Profile 2 (Moderate Emotional Labor/Moderate Surface Acting and High Deep Acting) and Profile 1 (High Emotional Labor), with most comparisons being statistically significant in both samples. In fact, only two of those comparisons turned out to be statistically non-significant in Sample 2 where the levels of work performance and psychological detachment proved to be similar across Profiles 2 (Moderate Emotional Labor/Moderate Surface Acting and High Deep Acting) and 3 (Low Emotional Labor/Low Surface Acting and Moderately Low Deep Acting). However, and consistent with the observation that explanatory similarity was not supported across samples, some statistically significant profile-specific differences were also noted. First, and consistent with the latent mean differences observed in the preliminary analyses, levels of psychological detachment were higher in Sample 2 than in Sample 1 for all three profiles. In addition, levels of job satisfaction were slightly higher in Sample 1 than in Sample 2 for members of Profile 1 (High Emotional Labor). Finally, levels of counterproductive work behaviors observed in Profile 3 proved to be slightly higher in Sample 1 (Low Emotional Labor) than in Sample 2 (Low Surface Acting and Moderately Low Deep Acting).

\section{Discussion}

Previous research has underscored the importance of distinguishing surface and deep acting (e.g., Hülsheger \& Schewe, 2011), as well as the hiding feelings and faking emotions components of surface acting (Lee \& Brotheridge, 2006) through the demonstration of well-differentiated effects on a variety of work outcomes, with surface acting being associated with a variety of undesirable outcomes (e.g., van Gelderen et al., 2017) and deep acting being rather associated with a variety of more desirable work 
outcomes (e.g., Huang et al., 2015). In addition, despite their distinctive nature, research has shown that these different emotional labor strategies tend to be positively related to one another (e.g., Lee \& Brotheridge, 2006). However, despite this known interrelation, relatively little attention has been allocated to understanding the joint effects of these various emotional labor strategies (Cheung \& Lun, 2015; Gabriel et al., 2015). The person-centered approach appears to be particularly well-suited to this investigation, providing us with a way to assess the emotional labor strategies combinations that are most frequently used by different profiles of employees, and the relative consequences of membership into these various profiles.

In the present study, we relied on LPA to identify subpopulations of workers characterized by distinct configurations of hiding feelings, faking emotions, and deep acting. In addition, using a methodological framework recently proposed by Morin, Meyer et al. (2016), we systematically assessed the generalizability of the profiles identified across two distinct samples of employees characterized by either, direct, intensive, and sustained, or limited, indirect, and/or sporadic contact with customers. Although slight differences emerged, the results provided evidence for the generalizability of the results obtained across both samples. Specifically, our results revealed that three distinct profiles, generally matching our expectations and prior variable- and person-centered results (Cheung \& Lun, 2015; Gabriel et al., 2015), best represented the emotional labor configurations in both samples. This similarity of results reinforces the robustness of our findings and the possible usefulness of devising intervention strategies targeting specific employee profiles.

The current results have many implications for emotional regulation research. Thus, prior variablecentered studies generally suggested that it might be important to distinguish between surface acting and deep acting strategies (e.g., Hülsheger \& Schewe, 2011). This assertion was supported by the present research when employees with limited, indirect, and/or sporadic contact with customers were considered. Indeed, by revealing two profiles characterized by diverging levels of surface acting and deep acting, our results show the added-value of distinguishing between these two emotional labor strategies, and support the assertion that employees with limited, indirect, and/or sporadic contact with customers are able to use different strategies to regulate their emotions in the workplace. In contrast, our results also show that this distinction might not be as meaningful for employees who have direct, intensive, and sustained contacts with their customers as these appear to use all three emotional labor strategies in an undifferentiated manner either at a low, moderate, or high level. Possibly, the more limited emotional labor demands posed on employees with limited, indirect, and/or sporadic contact with customers make it easier for them to rely on a more adaptive emotional labor strategy (i.e., deep acting, which was higher than surface acting in two out of three profiles).

In contrast, two other expectations were not met by the results. First, despite mounting variablecentered evidence regarding the differentiated nature of the hiding feelings and faking emotions components of surface acting (Lee \& Brotheridge, 2006), the present study suggested that all types of employees tend to rely on matching levels of these two components. As such, our results argue against the value of distinguishing among these two components of surface acting (e.g., Gillet, Morin, Cougot, \& Gagné, 2017). Second, despite tentative variable- and person-centered (e.g., Gabriel et al., 2015) evidence suggesting that the effects of surface acting might differ for workers also relying on either high, or low, levels of deep acting, we found no evidence for a profile characterized by high levels of surface acting and low levels of deep acting. This last observation suggests that higher levels of surface acting typically tend to accompany levels of deep acting that are at least equally high. Once again, this specific result was observed among both samples of employees.

Finally, ascertaining that profiles represent substantively meaningful subpopulations represents a critical aspect of construct validation and can be demonstrated through the generalization of profiles across samples (e.g., Meyer \& Morin, 2016). In the present study, we were able to identify profiles that generally displayed a similar configuration across two independent samples of employees with direct, intensive, and sustained versus limited, indirect, and/or sporadic contact with customers, while also showing that in two of these profiles, levels of deep acting tended to be systematically higher among employees with limited, indirect, and/or sporadic contact with customers. This finding underscores the need for future emotional labor research to gain a better understanding of emotional demands in different customer contact settings and systematically examine how occupational groups characterized by different types of customer contact deal with those demands and perform emotional labor.

\section{Outcomes of Emotional Labor Profiles}

Taken together, our results suggested that it is preferable for employees to rely on low (Profile 3) or 
moderate (Profile 2) levels of surface acting, regardless of their levels of deep acting, rather than rely on high levels of both strategies (Profile 1). Despite a few differences (most of which were related to the fact that levels of psychological detachment were higher in Sample 2 than in Sample 1), the nature of the profiles-outcomes associations was very similar across our two samples of French workers, thus reinforcing our interpretation that all profiles appear to tap into similar mechanisms across samples. Indeed, in line with our expectations (Chou et al., 2012; Gabriel et al., 2015), higher levels of job satisfaction, performance, and psychological detachment, as well as lower levels of emotional exhaustion, sleeping problems, and counterproductive work behaviors were associated with the Low Emotional Labor/Low Surface Acting and Moderately Low Deep Acting profile across samples. Likewise, the High Emotional Labor profile was associated with the most negative outcomes across both samples, whereas the Moderate Emotional Labor/Moderate Surface Acting and High Deep Acting fell in between.

When performing surface acting to match norms, workers may develop feelings of inauthenticity, thus discouraging them from reciprocating through positive behaviors toward the organization and encouraging them to display counterproductive work behaviors (Blau, 1964). Moreover, the wider the gap between organizational display rules and workers' genuine emotions, the less inclined workers may be to identify with their job, leading them to experience reduced levels of job satisfaction and an increased sense of psychological disconnection from their work (Heider, 1946). Such feelings of inauthenticity may make them less likely to experience healthy levels of psychological detachment and more likely to have sleeping problems given the links between surface acting and rumination (Liang et al., 2018).

More generally, our results support the idea that surface acting may eliminate the otherwise positive effects of deep acting (Huang et al., 2015) and that negative consequences are associated with the combined presence of surface and deep acting (Cheung \& Lun, 2015; Gabriel et al., 2015). As both surface acting and deep acting require resource expenditure (Hülsheger \& Schewe, 2011), the combined reliance on both strategies may lead to a depletion of resources. If employees cannot replenish their resource pool, the resulting strain may subsequently lead to detrimental outcomes (e.g., emotional exhaustion; Hobfoll, 1989). In sum, our results show that the beneficial effects of deep acting could be offset by the presence of hiding feelings and faking emotions. Although the results showed variations in the relative size and nature of the profile groups across the two samples, the combined presence of high levels of deep and surface acting did not occur frequently, as the High Emotional Labor profile was the least frequent in both samples (between 16 and $28 \%$ of the employees). Our findings also question the idea that the undesirable effects of surface acting could be satisfactorily countered by interventions focusing on increases in employees' levels of deep acting. Rather, they suggest that interventions would maximally benefit from decreasing surface acting regardless of the levels of deep acting. However, it is noteworthy that levels of work performance and psychological detachment were not significantly different across Profiles 2 (Moderate Surface Acting and High Deep Acting) and 3 (Low Surface Acting and Moderately Low Deep Acting) in Sample 2. It is possible that the levels of hiding feelings and faking emotions were not sufficiently high in Sample 2 to generate undesirable outcomes when combined with higher levels of deep acting. Future research is needed to achieve a clearer understanding of the costs and benefits associated with deep acting as a compensatory mechanism for surface acting.

\section{Predictors of Emotional Labor Profiles}

This study also sought to address the scarcity of research on the individual and social factors that may be associated with emotional labor profiles (e.g., Gabriel et al., 2015). We examined whether age, sex, and perceived workload as well as employee's perception of the social support received from their organization, their supervisor, and their colleagues, were associated with profile membership. A first important finding was that the relations between the predictors and the likelihood of membership into the various profiles were similar across the two samples of employees studied. This result thus supports the idea that the profiles identified across these two samples tap into similar emotional labor mechanisms despite being slightly different across samples. More precisely, low or moderate levels of surface acting may make it easier for employees to rely on higher levels of deep acting but this possibility is not realized as often among those involved in direct, intensive, and sustained interactions with customers. Naturally, additional research will be needed to verify this interpretation.

Females were two times more likely than males to be members of the High Emotional Labor (1) profile relative to the other two profiles. This observation is aligned with previous results showing that females tend to engage in significantly more emotional labor than men (Lovell, Lee, \& Brotheridge, 2009), and that males and females could be exposed to slightly different norms and display rules (Vaccaro, 
Schrock, \& McCabe, 2011). In particular, males tend to be ascribed slightly higher levels of authority and status, which could shield them from the expression of negative emotions by their customers, thus leading them to rely less intensively on emotional labor (Cottingham et al., 2015). In line with prior results (Brotheridge \& Lee, 2011), age was unrelated to the likelihood of membership into any of the profiles.

Our results also showed that perceived workload predicted a higher likelihood of membership into the High Emotional Labor and Moderate Emotional Labor/Moderate Surface Acting and High Deep Acting profiles relative to the Low Emotional Labor/Low Surface Acting and Moderately Low Deep Acting profile. This observation matches variable-centered research suggesting that workload is associated with an increased reliance on surface acting (Tuxford \& Bradley, 2015). It also extends on this previous research by showing that this association is not limited to surface acting, but also involves deep acting. Our findings thus confirm that job demands such as workload are situational cues for the emotion regulation process (Grandey, 2000). Workers facing higher workloads may be more prone to experiencing negative emotions as a result of this workload, which could trigger compensatory strategies aiming to regulate their emotional expressions to match organizational display rules (e.g., Mesmer-Magnus et al., 2012).

Our results finally showed associations between employees' perceptions of supervisor support and an increased likelihood of membership into the Low Emotional Labor/Low Surface Acting and Moderately Low Deep Acting profile relative to the remaining profiles, whereas perceived organizational support predicted an increased likelihood of membership into the Moderate Emotional Labor/Moderate Surface Acting and High Deep Acting profile relative to the High Emotional Labor profile. Despite not being aligned with our expectations (also see Hur et al., 2015), mainly because the profiles did not fully match those expectations, these results still support those from prior research (Chou et al., 2012) showing that workers who perceive less organizational and supervisor support tend to rely more on taxing emotional labor strategies such as surface acting. Indeed, employees who perceive low levels of organizational and supervisor support are less likely to engage in their job and to make meaningful contributions to their organization (Caesens et al., 2014). They also put less effort towards experiencing the expected emotions, being more interested in short-term success. Thus, they tend to adopt surface acting by hiding their feelings or faking the appropriate emotional display (Mishra, 2014). In contrast, support from the colleagues did not have any desirable or undesirable effects on emotional labor. These results are aligned with those from Caesens et al. (2014), who showed that distinct sources of support sometimes yield differentiated effects. Future research is needed to look at a broader set of theoretically relevant predictors of profile membership (e.g., display rule perceptions, person-organization fit; Diefendorff \& Richard, 2003) to unpack the mechanisms underlying the relation between sources of social support and emotional labor profiles.

Examining employees' perception of the importance of display rules for their job in the prediction of profile membership seems particularly important. Indeed, emotional display rules should represent a much more salient antecedent of profile membership among workers with direct, intensive, and sustained contacts with customers than among workers with limited, indirect, and/or sporadic contact with customers. Consistent with this idea, a study by Diefendorff and Richard (2003), conducted among employees from a variety of organizations and occupations, suggested that the more workers perceive that their job require interpersonal interactions, the more they perceive display rules to be important. These authors also showed that display rules perceptions influenced employees' emotion management behaviors. Thus, future research is needed to examine the connection between display rules and emotional labor profiles among groups of workers with different types of contact with customers.

\section{Limitations and Perspectives for Future Research}

The present results has limitations that should be addressed in future research. First, we relied on selfreport measures, suggesting that results might be impacted by social desirability and common method biases. Additional research should be conducted using more objective data (e.g., records of absenteeism, turnover or performance), as well as informant-reported measures of environmental characteristics and work outcomes. Second, we used single-item measures to assess job satisfaction and work performance. Yet, it is well known that such measures tend to be less reliable than multi-item measures, and not as good at providing a complete content coverage of the construct under study. In addition, the scale score reliability of our measure of counterproductive work behaviors remained low $(\alpha=.57$ in Sample 1 and .69 in Sample 2), which is to be expected for a checklist of otherwise unrelated counterproductive work behaviors (in contrast to more typical measures tapping into conceptually interrelated behaviors; Streiner, 2003). Still, it is important to keep in mind that Cronbach alpha is also known to represent a lower bound for reliability estimates (Sijtsma, 2009). In the present study, more accurate composite reliability estimates 
obtained from the preliminary measurement models were more satisfactory $(\omega=.701$ across samples). In addition, all analyses reported in this study rely on factor scores taken from these preliminary measurement models, which are known to incorporate a partial control for measurement errors (Skrondal \& Laake, 2001). Still, it would be interesting for future research to replicate our results using more robust measures.

Third, our research is based on a cross-sectional design, making it impossible to reach clear conclusions regarding the directionality of the observed associations among constructs. As such, future research would benefit from longitudinal studies allowing for a more precise investigation of the stability of profiles over time, and the direction of the associations between the profiles, their determinants, and their outcomes. Fourth, although we assessed the construct validity of the emotional labor profiles identified in this study through a consideration of their association with a range of predictors (including perceived organizational, supervisor, and colleagues support, and workload), some other important predictors of profile membership (e.g., personality or display rule perceptions) were not examined in this study due to space limitations. For instance, future studies may examine the role of individual differences (e.g., personality) and of more directly assessed indicators of the existence, strength, specificity, and direction of each occupation's display rules in terms of profile membership. A fifth limitation is related to our reliance on samples of employees from a range of different occupations, differing from one another on more than one characteristic. For instance, employees from Sample 1 are likely to differ in terms of clientele (i.e., students or patients), contexts in which customer contacts take place (i.e., schools or hospitals), and level of education. Although including different occupational groups increases the generalizability of our findings to a range of occupations, it also means that the two samples differ from one another on more than one characteristics, and that within-sample differences might have obscured additional meaningful differences. It would be interesting for future research relying on larger samples to assess the extent to which our results extend to an even more diversified range of occupational groups considered on their own rather than in combination.

\section{Practical Implications and Conclusions}

Several recommendations for practice emerge from this study. First, workers displaying high levels of surface acting appear to be at risk for a variety of undesirable outcomes. Organizations should thus be aware of the detrimental effects of surface acting, and given tools to understand, detect, and prevent the over-reliance on faking and hiding emotions. From an organisational perspective, training workshops should be provided in order to discourage the use of surface acting in the workplace and encourage employees to identify healthy ways to articulate their authentic emotions (Grandey et al., 2015). Organizations should also avoid situations where workload becomes unreasonably high to help reduce employees' need to rely on surface acting. Organizations need to understand that work overload comes at a cost and acknowledge employees' efforts through their human resource policies and practices. For instance, Blay, Roche, Duffield, and Gallagher (2017) demonstrated that the transfer of patients in nursing takes an important toll on the workload. Thus, nursing workload measurement systems should take into account the rate of ward and bed transfers in order to more accurately reflect staffing needs. Similarly, teachers' workloads are generally defined in terms of direct teaching hours in the classroom. However, teachers' workload also involves a plethora of administrative and clerical duties that also take an important toll on their workload. Yet, teachers often lack the training required to perform these additional duties efficiently. Thus, school leaders and policymakers should seek to create a better alignment between the many nonteaching demands placed on teachers and the professional standards teachers set for themselves in terms of their main teaching tasks (Van Droogenbroeck, Spruyt, \& Vanroelen, 2014).

Organizations should also support the development of resources (e.g., interpersonal influence, role identification) known to be negatively related to surface acting (Brotheridge \& Lee, 2002). Furthermore, mindfulness-based interventions may help employees diminish their use of surface acting (Hülsheger, Alberts, Feinholdt, \& Lang, 2013). Organizations could also conduct focus groups with employees in order to collectively identify ways to allow them to display genuine emotions while meeting norms (Huyghebaert et al., 2017). To take surface acting prevention one step further, managers and practitioners should show concern for the extent to which their employees feel supported by their organizations and supervisors and foster these perceptions. Recently, Gonzalez-Morales, Kernan, Becker, and Eisenberger (2016) provided evidence for the effectiveness of a brief supervisor support training program including four strategies (i.e., benevolence, sincerity, fairness, and experiential processing). Among other ways to achieve this objective, top management might promote a supportive culture within their organization, for instance, by providing to employees the resources they need to perform they job effectively, by providing assurance of security during stressful times, and by promoting justice and fairness in the 
way policies are implemented and rewards distributed (Eisenberger \& Stinglhamber, 2011).

\section{References}

Adriaenssens, J., De Gucht, V., \& Maes, S. (2015). Determinants and prevalence of burnout in emergency nurses: A systematic review of 25 years of research. International Journal of Nursing Studies, 52, 649-661.

Belt, A., \& Belt, P. (2017). Teachers' differing perceptions of classroom disturbances. Educational Research, 59, 54-72.

Blau, P.M. (1964). Exchange and power in social life. New York: John Wiley.

Blay, N., Roche, M., Duffield, C., \& Gallagher, R. (2017). Intrahospital transfers and the impact on nursing workload. Journal of Clinical Nursing, 26, 4822-4829.

Bozionelos, N., \& Kiamou, K. (2008). Emotion work in the Hellenic frontline services environment: How it relates to emotional exhaustion and work attitudes. The International Journal of Human Resource Management, 19, 1108-1130.

Brotheridge, C. M., \& Grandey, A. A. (2002). Emotional labor and burnout: Comparing two perspectives of "people work". Journal of Vocational Behavior, 60, 17-39.

Brotheridge, C.M., \& Lee, R.T. (2003). Development and validation of the Emotional Labour Scale. Journal of Occupational and Organizational Psychology, 76, 365-379.

Caesens, G., Stinglhamber, F., \& Luypaert, G. (2014). The impact of work engagement and workaholism on well-being: The role of work-related social support. Career Development International, 19, 813-835.

Cheung, F., \& Lun, V.M.-C. (2015). Emotional labor and occupational well-being: A latent profile analytic approach. Journal of Individual Differences, 36, 30-37.

Chou, H., Hecker, R., \& Martin, A. (2012). Predicting nurses' well-being from job demands and resources: A cross-sectional study. Journal of Nursing Management, 20, 502-511.

Cottingham, M., Erickson, R. \& Diefendorff, J. (2015). Examining men's status shield and status bonus: How gender frames emotional labor and job satisfaction in nurses. Sex Roles, 72, 377-389.

Diallo, T.M.O., Morin, A.J.S., \& Lu, H. (2017). The impact of total and partial inclusion or exclusion of active and inactive time invariant covariates in growth mixture. Psychological Methods, 22, 166-190.

Diefendorff, J. M., \& Richard, E. M. (2003). Antecedents and consequences of emotional display rule perceptions. Journal of Applied Psychology, 88, 284-294.

Enders, C.K. (2010). Applied missing data analysis. New York: Guilford.

Eisenberger, R., Huntington, R., Hutchison, S., \& Sowa, D. (1986). Perceived organizational support. Journal of Applied Psychology, 71, 500-507.

Eisenberger, R., \& Stinglhamber, F. (2011). Perceived organizational support: Fostering enthusiastic and productive employees. Washington: APA Books.

Gabriel, A.S., Daniels, M.A., Diefendorff, J.M., \& Greguras, G.J. (2015). Emotional labor actors: A latent profile analysis of emotional labor strategies. Journal of Applied Psychology, 100, 863-879.

Gillet, N., Morin, A.J.S., Cougot, B., \& Gagné, M. (2017). Workaholism profiles: Associations with determinants, correlates, and outcomes. Journal of Occupational and Organizational Psychology, 90, 559-586.

Goldberg, L.S., \& Grandey, A.A. (2007). Display rules versus display autonomy: Emotion regulation, emotional exhaustion, and task performance in a call center simulation. Journal of Occupational Health Psychology, 12, 301-318.

Gonzalez-Morales, M., Kernan, M.C., Becker, T.E., \& Eisenberger, R. (2016). Defeating abusive supervision: Training supervisors to support subordinates. Journal of Occupational Health Psychology. Early view doi 10.1037/ocp0000061

Grandey, A.A. (2000). Emotion regulation in the workplace: A new way to conceptualize emotional labor. Journal of Occupational Health Psychology, 5, 95-110.

Grandey, A.A., Rupp, D., \& Brice, W.N. (2015). Emotional labor threatens decent work: A proposal to eradicate emotional display rules. Journal of Organizational Behavior, 36, 770-785.

Gray, B. (2010). Emotional labour, gender and professional stereotypes of emotional and physical contact, and personal perspectives on the emotional labour of nursing. Journal of Gender Studies, 19, 349-360.

Hargreaves, A. (1998). The emotional practice of teaching. Teaching \& Teacher Education, 14, 835-854.

Heider, F. (1946). Attitudes and cognitive organization. Journal of Psychology, 21, 107-112. 
Henderson, A. (2001). Emotional labor and nursing: An under-appreciated aspect of caring work. Nursing Inquiry, 8, 130-138.

Hipp, J.R., \& Bauer, D.J. (2006). Local solutions in the estimation of growth mixture models. Psychological Methods, 11, 36-53.

Hobfoll, S.E. (1989). Conservation of resources: A new attempt at conceptualizing stress. American Psychologist, 44, 513-524.

Hochschild, A. R. (1983). The managed heart. Berkley, CA: University of California.

Huang, J.L., Chiaburu, D.S., Zhang, X.-A., Li, N., \& Grandey, A.A. (2015). Rising to the challenge: Deep acting is more beneficial when tasks are appraised as challenging. Journal of Applied Psychology, 100, 1398-1408.

Hülsheger, U.R., Alberts, H.J.E.M., Feinholdt, A., \& Lang, J.W.B. (2013). Benefits of mindfulness at work: The role of mindfulness in emotion regulation, emotional exhaustion, and job satisfaction. Journal of Applied Psychology, 98, 310-325.

Hülsheger, U.R., \& Schewe, A.F. (2011). On the costs and benefits of emotional labor: A metaanalysis of three decades of research. Journal of Occupational Health Psychology, 16, 361-389.

Hur, W.-M., Han, S.-J., Yoo, J.-J., \& Moon, T.W. (2015). The moderating role of perceived organizational support on the relationship between emotional labor and job-related outcomes. Management Decision, 53, 605-624.

Huyghebaert, T., Gillet, N., Fernet, C., Lahiani, F.-J., Chevalier, S., \& Fouquereau, E. (2017). Investigating the longitudinal effects of surface acting on managers' functioning through psychological needs. Journal of Occupational Health Psychology. Early view doi 10.1037/ocp0000080

Huynh, T., Alderson, M., \& Thompson, M. (2008). Emotional labour underlying caring: An evolutionary concept analysis. Journal of Advanced Nursing, 64, 195-208.

Jenkins, C.D., Stanton, B., Niemcryk, S.J., Rose, R.M. (1988). A scale for estimation of sleep problems in clinical research. Journal of Clinical Epidemiology, 41, 313-321.

Kessler, R.C., Barber, C., Beck, A., Berglund, P., Cleary, P.D., McKenas, D., \& Pronk, N. (2003). The world health organization health and work performance questionnaire (HPQ). Journal of Occupational and Environmental Medicine, 45, 156-174.

Lapointe, É., Morin, A.J.S., Courcy, F., Boilard, A., \& Payette, D. (2012). Workplace affective commitment, emotional labor strategies and burnout: A multiple mediator model. The International Journal of Business and Management, 7, 3-21.

Lee, R., \& Brotheridge, C. (2006). When prey turns predatory: Workplace bullying as a predictor of counter aggression/bullying, coping, and wellbeing. European Journal of Work and Organizational Psychology, 15, 352-377.

Liang, L.H., Brown, D.J., Ferris, D.L., Hanig, S., Lian, H., \& Keeping, L.M. (2018). The dimensions and mechanisms of mindfulness in regulating aggressive behaviors. Journal of Applied Psychology, 103, 281-299.

Lovell, B.L., Lee, R.T., \& Brotheridge, C.M. (2009). Gender differences in the application of communication skills, emotional labor, stress-coping, and well-being among Canadian physicians. Archives: The International Journal of Medicine, 2, 273-278.

Mann, S. (2004). 'People-work': emotion management, stress and coping. British Journal of Guidance \& Counselling, 32, 205-221.

Marsh, H.W., Lüdtke, O., Trautwein, U., \& Morin, A.J.S. (2009). Latent profile analysis of academic self-concept dimensions: Synergy of person- and variable-centered approaches to the internal/external frame of reference model. Structural Equation Modeling, 16, 1-35.

McVicar, A. (2016). Scoping the common antecedents of job stress and job satisfaction for nurses using the job demands-resources model of stress. Journal of Nursing Management, 24, E112-E136.

Mesmer-Magnus, J.R., DeChurch, L., \& Wax, A. (2012). Moving emotional labor beyond surface and deep acting: A discordance-congruence perspective. Organizational Psychology Review, 2, 6-53.

Meyer, J.P., \& Morin, A.J.S. (2016). A person-centered approach to commitment research: Theory, research, and methodology. Journal of Organizational Behavior, 37, 584-612.

Millsap, R.E. (2011). Statistical approaches to measurement invariance. New York: Taylor \& Francis.

Mishra, S.K. (2014). Linking perceived organizational support to emotional labor. Personnel Review, $43,845-860$.

Morin, A.J.S. (2016). Person-centered research strategies in commitment research. In J.P. Meyer (Ed.), 
The handbook of employee commitment (p. 490-508). Cheltenham: Edward Elgar.

Morin, A.J.S., Meyer, J.P., Creusier, J., \& Biétry, F. (2016). Multiple-group analysis of similarity in latent profile solutions. Organizational Research Methods, 19, 231-254.

Morin, A.J.S., Morizot, J., Boudrias, J.-S., \& Madore, I. (2011). A multifoci person-centered perspective on workplace affective commitment: A latent profile/factor mixture analysis. Organizational Research Methods, 14, 58-90.

Morin, A.J.S., \& Wang, J.C.K. (2016). A gentle introduction to mixture modeling using physical fitness data. In N. Ntoumanis \& N. Myers (Eds.), An introduction to intermediate and advanced statistical analyses for sport and exercise scientists (pp. 183-210). London: Wiley.

Morris, A.J., \& Feldman, D.C. (1996). The dimensions, antecedents, and consequences of emotional labor. Academy of Management Review, 21, 986-1010.

Muthén, L.K., \& Muthén, B.O. (2017). Mplus user's guide. Los Angeles: Muthén \& Muthén.

Raykov, T., \& Marcoulides, G.A. (2004). Using the delta method for approximate interval estimation of parameter functions in SEM. Structural Equation Modeling, 11, 621-637.

Rupp, D.E., \& Spencer, S. (2006). When customers lash out: The effects of customer interactional injustice on emotional labor and the mediating role of discrete emotions. Journal of Applied Psychology, 91, 971-978.

Schaufeli, W.B., Leiter, M.P., Maslach, C., \& Jackson, S.E. (1996). MBI general survey. In C. Maslach., S.F. Jackson, \& M.P. Leiter (Eds.), Maslach burnout inventory manual (pp. 19-26). Palo Alto: Consulting Psychologists Press.

Seger-Guttmann, T., \& Medler-Liraz, H. (2016). The costs of hiding and faking emotions: The case of extraverts and introverts. The Journal of Psychology: Interdisciplinary and Applied, 150, 342-357.

Shimazu, A., Schaufeli, W.B., Kamiyama, K., \& Kawakami, N. (2015). Workaholism vs. work engagement: The two different predictors of future well-being and performance. International Journal of Behavioral Medicine, 22, 18-23.

Sijtsma, K. (2009). On the use, misuse, and the very limited usefulness of Cronbach's alpha. Psychometrika, 74, 107-120.

Simpson, P.A., \& Stroh, L.K. (2004). Gender differences: Emotional expression and feelings of personal inauthenticity. Journal of Applied Psychology, 89, 715-721.

Skaalvik, E.M., \& Skaalvik, S. (2010). Teacher self-efficacy and teacher burnout. Teaching and Teacher Education, 26, 1059-1069.

Skrondal, A., \& Laake, P. (2001). Regression among factor scores. Psychometrika, 66, 563-576.

Sonnentag, S., \& Fritz, C. (2007). The recovery experience questionnaire. Journal of Occupational Health Psychology, 12, 204-221.

Spector, P.E., Bauer, J.A., \& Fox, S. (2010). Measurement artifacts in the assessment of counterproductive work behavior and organizational citizenship behavior: Do we know what we think we know? Journal of Applied Psychology, 95, 781-790.

Spector, P.E., \& Jex, S.M. (1998). Development of four self-report measures of job stressors and strain: Interpersonal Conflict at Work Scale, Organizational Constraints Scale, Quantitative Workload Inventory, and Physical Symptoms Inventory. Journal of Occupational Health Psychology, 3, 356-367.

Streiner, D.L. (2003). Starting at the beginning: An introduction to coefficient alpha and internal consistency. Journal of Personality Assessment, 80, 99-103.

Sutton, R. E., \& Wheatley, K. F. (2003). Teachers' emotions and teaching: A review of the literature and directions for future research. Educational Psychology Review, 15, 327-358.

Tuxford, L.M., \& Bradley, G.L. (2015). Emotional job demands and emotional exhaustion in teachers. Educational Psychology, 35, 1006-1024.

Vaccaro, C.A., Schrock, D.P., \& McCabe, J.M. (2011). Managing emotional manhood: Fighting and fostering fear in mixed martial arts. Social Psychology Quarterly, 74, 414-437.

Van Droogenbroeck, F., Spruyt, B., \& Vanroelen, C. (2014). Burnout among senior teachers: Investigating the role of workload and interpersonal relationships at work. Teaching and Teacher Education, 43, 99-109.

van Gelderen, B.R., Konijn, E.A., \& Bakker, A.B. (2017). Emotional labor among police officers: A diary study relating strain, emotional labor, and service performance. The International Journal of Human Resource Management, 28, 852-879.

Yoo, J., \& Arnold, T.J. (2016). Frontline employee customer-oriented attitude in the presence of job 
demands and resources. Journal of Service Research, 19, 102-117.

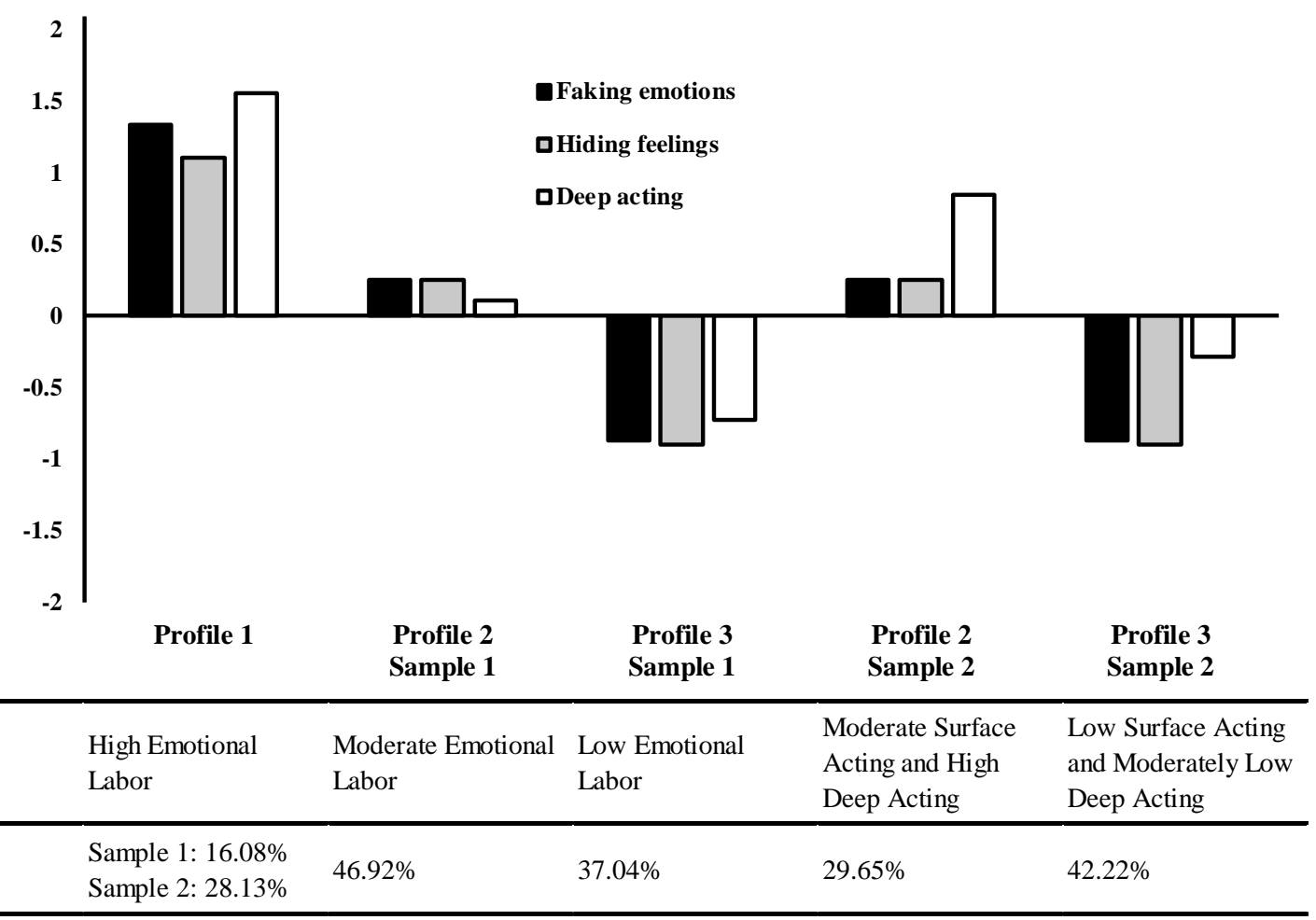

Figure 1. Final Latent Profile Solution. 
Table 1

Number and Characteristics of Profiles in Prior Research

\begin{tabular}{|c|c|c|}
\hline & Characteristics & Covariates \\
\hline \multicolumn{3}{|l|}{ Cheung and Lu (2015) } \\
\hline Profile 1 active actors & $\begin{array}{l}\text { High levels of surface acting, deep acting, and expression of } \\
\text { naturally felt emotions }\end{array}$ & Emotional exhaustion: $2>1>3$ \\
\hline \multirow{2}{*}{$\begin{array}{l}\text { Profile } 2 \text { display rules } \\
\text { compliers }\end{array}$} & \multirow{2}{*}{$\begin{array}{l}\text { High levels of surface acting and deep acting, and low levels of } \\
\text { expression of naturally felt emotions }\end{array}$} & Depersonalization: $2>1>3$ \\
\hline & & Lack of performance accomplishment: $2>1>3$ \\
\hline $\begin{array}{l}\text { Profile } 3 \text { emotionally } \\
\text { congruent employees }\end{array}$ & $\begin{array}{l}\text { High levels of deep acting and expression of naturally felt } \\
\text { emotions, and moderate levels of surface acting }\end{array}$ & Job satisfaction: $3=1>2$ \\
\hline \multicolumn{3}{|l|}{ Gabriel et al. (2015) } \\
\hline Profile 1 deep actors & Very low levels of deep and surface acting & Display rules in the US sample: $1=4=5>2 ; 4>3$ \\
\hline Profile 2 non-actors & Low to moderate levels of deep and surface acting & Display rules in the Singapore sample: $4>1>2=3 ; 4>5>2$ \\
\hline Profile 3 low actors & Low levels of deep acting and high levels of surface acting & Positive affect in the US sample: $1>2=3=4>5$ \\
\hline Profile 4 regulators & High levels of deep acting and low levels of surface acting & Positive affect in the Singapore sample: $1=3>4$ \\
\hline \multirow[t]{9}{*}{ Profile 5 surface actors } & High levels of deep and surface acting & Negative affect in the US sample: $4=5>1=2=3$ \\
\hline & & Negative affect in the Singapore sample: $4>3$ \\
\hline & & Customer orientation in the Singapore sample: $1=2=3=4>5$ \\
\hline & & Emotion demands-abilities fit in the Singapore sample: $2>1=3=4=5$ \\
\hline & & Emotional exhaustion in the US sample: $5>4>1=2=3$ \\
\hline & & Emotional exhaustion in the Singapore sample: $4=5>1=3>2$ \\
\hline & & Job satisfaction in the US sample: $1>2>3>4>5$ \\
\hline & & Job satisfaction in the Singapore sample: $3>1=2>4>5$ \\
\hline & & Felt inauthenticity in the Singapore sample: $5>4>1=3>2$ \\
\hline
\end{tabular}


Table 2

Correlations between Variables Used in the Present Study in Samples 1 (Above the Diagonal) and 2 (Below the Diagonal)

\begin{tabular}{|c|c|c|c|c|c|c|c|c|c|c|c|c|c|c|c|}
\hline Variable & 1 & 2 & 3 & 4 & 5 & 6 & 7 & 8 & 9 & 10 & 11 & 12 & 13 & 14 & 15 \\
\hline \multicolumn{16}{|l|}{ Demographics } \\
\hline 1. Sex & - & $-.11 *$ & .00 & .06 & -.03 & -.04 & -.03 & .05 & .04 & .03 & .06 & .07 & -.03 & .08 & -.03 \\
\hline 2. Age & $.28 * *$ & - & -.08 & -.06 & -.01 & .05 & .00 & $-.16^{* *}$ & $.13^{*}$ & -.05 & .08 & -.03 & .01 & -.03 & $.14^{*}$ \\
\hline \multicolumn{16}{|l|}{ Emotional labor strategies } \\
\hline 3. Faking emotions ${ }^{1}$ & $.23^{* *}$ & $.14^{*}$ & - & $.73 * *$ & $.76^{* *}$ & $-.18 * *$ & $-.24 * *$ & $-.15^{* *}$ & $.28 * *$ & $.46^{* *}$ & $.34 * *$ & $-.33 * *$ & $.23 * *$ & $-.29 * *$ & $-.34 * *$ \\
\hline 4. Hiding feelings ${ }^{1}$ & $.24 * *$ & $.15^{*}$ & $.83 * *$ & - & $.65 * *$ & $-.23 * *$ & $-.27 * *$ & $-.28 * *$ & $.34 * *$ & $.48 * *$ & $.32 * *$ & $-.30 * *$ & $.20 * *$ & $-.31 * *$ & $-.31 * *$ \\
\hline 5. Deep acting ${ }^{1}$ & .03 & .03 & $.79 * *$ & $.77 * *$ & - & -.03 & -.08 & $-.12 *$ & $.21 * *$ & $.39 * *$ & $.26 * *$ & $-.22 * *$ & $.24 * *$ & $-.24 * *$ & $-.29 * *$ \\
\hline \multicolumn{16}{|l|}{ Predictors } \\
\hline $\begin{array}{l}\text { 6. Perceived organizational } \\
\text { support }^{1}\end{array}$ & $-.20 * *$ & $-.23 * *$ & $-.40 * *$ & $-.41 * *$ & $-.31 * *$ & - & $.85^{* *}$ & $.25^{* *}$ & $-.43 * *$ & $-.36^{* *}$ & $-.27 * *$ & $.21 * *$ & $-.15 * *$ & $.43 * *$ & $.25 * *$ \\
\hline $\begin{array}{l}\text { 7. Perceived supervisor } \\
\text { support }^{1}\end{array}$ & $-.13^{*}$ & $-.16^{* *}$ & $-.35^{* *}$ & $-.37 * *$ & $-.30 * *$ & $.87 * *$ & - & $.23 * *$ & $-.36 * *$ & $-.38 * *$ & $-.22 * *$ & $.29 * *$ & $-.16^{* *}$ & $.42 * *$ & $.30 * *$ \\
\hline $\begin{array}{l}\text { 8. Perceived colleagues } \\
\text { support }^{1}\end{array}$ & .10 & -.07 & -.04 & -.05 & -.08 & $.28 * *$ & $.33^{* *}$ & - & $-.18 * *$ & $-.15 * *$ & $-.19 * *$ & $.13 *$ & $-.18 * *$ & $.28 * *$ & .11 \\
\hline 9. Workload ${ }^{1}$ & .07 & $.22 * *$ & $.34 * *$ & $.37 * *$ & $.37 * *$ & $-.46 * *$ & $-.34 * *$ & $-.18 * *$ & - & $.52 * *$ & $.41 * *$ & $-.47 * *$ & $.16^{* *}$ & $-.32 * *$ & $-.22 * *$ \\
\hline \multicolumn{16}{|l|}{ Outcomes } \\
\hline 10. Emotional exhaustion ${ }^{1}$ & $.24 * *$ & $.18 * *$ & $.53 * *$ & $.57 * *$ & $.42 * *$ & $-.61 * *$ & $-.53 * *$ & $-.12 *$ & $.45^{* *}$ & - & $.61 * *$ & $-.53 * *$ & $.29 * *$ & $-.52 * *$ & $-.43 * *$ \\
\hline 11. Sleeping problems ${ }^{1}$ & $.24 * *$ & $.21 * *$ & $.47 * *$ & $.50 * *$ & $.38 * *$ & $-.45 * *$ & $-.41 * *$ & -.06 & $.33 * *$ & $.69 * *$ & - & $-.40 * *$ & $.24 * *$ & $-.33 * *$ & $-.28 * *$ \\
\hline $\begin{array}{l}\text { 12. Psychological } \\
\text { detachment }^{1}\end{array}$ & $-.11 *$ & -.02 & $-.28 * *$ & $-.32 * *$ & $-.29 * *$ & $.33 * *$ & $.28 * *$ & .09 & $-.31 * *$ & $-.44 * *$ & $-.46 * *$ & - & $-.14 * *$ & $.35^{* *}$ & $.28 * *$ \\
\hline $\begin{array}{l}\text { 13. Counterproductive } \\
\text { work behaviors }{ }^{1}\end{array}$ & .01 & .07 & $.29 * *$ & $.30 * *$ & $.23 * *$ & $-.29 * *$ & $-.26 * *$ & -.08 & $.14^{*}$ & $.36^{* *}$ & $.34 * *$ & -.03 & - & $-.13^{*}$ & -.07 \\
\hline 14. Job Satisfaction & $-.16^{* *}$ & $-.17 * *$ & $-.47 * *$ & $-.47 * *$ & $-.34 * *$ & $.63 * *$ & $.54 * *$ & .09 & $-.36 * *$ & $-.69 * *$ & $-.46 * *$ & $.32 * *$ & $-.28 * *$ & - & $.44 * *$ \\
\hline 15. Work Performance & $-.15^{* *}$ & $-.12 *$ & $-.28 * *$ & $-.28 * *$ & $-.21 * *$ & $.32 * *$ & $.30 * *$ & .07 & $-.32 * *$ & $-.43 * *$ & $-.36 * *$ & $.25^{* *}$ & $-.14 *$ & $.35 * *$ & - \\
\hline
\end{tabular}

Note. $* p<.05 ; * * p<.01 ;{ }^{1}$ : The profile indicators are estimated from factor scores with a standard deviation of 1 and a grand mean of 0. 
Table 3

Results from Multinomial Logistic Regressions for the Effects of the Predictors on Profile Membership (Predictive Similarity)

\begin{tabular}{|c|c|c|c|c|c|c|}
\hline & \multicolumn{2}{|c|}{ Profile 1 vs. Profile 3} & \multicolumn{2}{|c|}{ Profile 2 vs. Profile 3} & \multicolumn{2}{|c|}{ Profile 1 vs. Profile 2} \\
\hline & Coef. (SE) & OR & Coef. (SE) & OR & Coef. (SE) & OR \\
\hline Age (standardized) & $-.195(.143)$ & .823 & $-.057(.124)$ & .944 & $-.138(.151)$ & .871 \\
\hline $\begin{array}{l}\text { Sex ( } 0 \text { male and } 1 \\
\text { females) }\end{array}$ & $.724(.334)^{*}$ & 2.063 & $-.115(.234)$ & .985 & $.739(.327)^{*}$ & 2.094 \\
\hline $\begin{array}{l}\text { Perceived } \\
\text { Organizational Support }\end{array}$ & $-.139(.266)$ & .870 & $.429(.246)$ & 1.535 & $-.568(.278)^{*}$ & .567 \\
\hline $\begin{array}{l}\text { Perceived Supervisor } \\
\text { Support }\end{array}$ & $-.660(.250)^{* *}$ & .517 & $-.667(.230)^{* * *}$ & .513 & $.007(.257)$ & 1.007 \\
\hline $\begin{array}{l}\text { Perceived Colleagues } \\
\text { Support }\end{array}$ & $-.115(.133)$ & .892 & $.006(.131)$ & 1.006 & $-.121(.130)$ & .886 \\
\hline Perceived Workload & $.965(.171)^{* *}$ & 2.624 & $.711(.143)^{* *}$ & 2.037 & $.253(.179)$ & 1.288 \\
\hline
\end{tabular}

Note. $* p<.05 ; * * p<.01 ;$ SE: Standard Error of the coefficient; OR: Odds Ratio; The coefficients and OR reflects the effects of the predictors on the likelihood of membership into the first listed profile relative to the second listed profile; Profile 1: High Emotional Labor; Profile 2: Moderate Emotional Labor in Sample 1 and Moderate Surface Acting and High Deep Acting in Sample 2; Profile 3: Low Emotional Labor in Sample 1 and Low Surface Acting and Moderately Low Deep Acting in Sample 2.

Table 4

Associations between Profile Membership and the Outcomes

\begin{tabular}{|c|c|c|c|c|}
\hline & $\begin{array}{c}\text { Profile } 1 \\
\text { Mean }[\mathrm{CI}]\end{array}$ & $\begin{array}{c}\text { Profile } 2 \\
\text { Mean }[\mathrm{CI}]\end{array}$ & $\begin{array}{c}\text { Profile } 3 \\
\text { Mean [CI] }\end{array}$ & $\begin{array}{l}\text { Significant } \\
\text { Differences }\end{array}$ \\
\hline \multicolumn{5}{|l|}{ Job Satisfaction } \\
\hline Sample 1 & $2.274[2.054 ; 2.494]$ & $2.694[2.586 ; 2.802]$ & $3.023[2.915 ; 3.131]$ & $3>2>1$ \\
\hline Sample 2 & $1.880[1.702 ; 2.058]$ & $2.813[2.658 ; 2.968]$ & $3.083[2.961 ; 3.205]$ & $3>2>1$ \\
\hline Difference Samples 1 vs 2 & Sample $1>2$ & Sample $1=2$ & Sample $1=2$ & \\
\hline \multicolumn{5}{|l|}{ Work Performance } \\
\hline Sample 1 & $5.144[4.487 ; 5.801]$ & $6.763[6.508 ; 7.018]$ & $7.355[7.126 ; 7.584]$ & $3>2>1$ \\
\hline Sample 2 & $5.742[5.242 ; 6.242]$ & $7.004[6.657 ; 7.351]$ & $7.409[7.193 ; 7.625]$ & $3=2>1$ \\
\hline Difference Samples 1 vs 2 & Sample $1=2$ & Sample $1=2$ & Sample $1=2$ & \\
\hline \multicolumn{5}{|l|}{ Emotional exhaustion } \\
\hline Sample 1 & $.829[.625 ; 1.033]$ & $.169[.024 ; .314]$ & $-.615[-.776 ;-.454]$ & $1>2>3$ \\
\hline Sample 2 & $1.028[.871 ; 1.185]$ & $-.076[-.268 ; .116]$ & $-.607[-.760 ;-.454]$ & $1>2>3$ \\
\hline Difference Samples 1 vs 2 & Sample $1=2$ & Sample $1=2$ & Sample $1=2$ & \\
\hline \multicolumn{5}{|l|}{ Sleeping problems } \\
\hline Sample 1 & $.635[.402 ; .868]$ & $.128[-.021 ; .277]$ & $-.394[-.566 ;-.222]$ & $1>2>3$ \\
\hline Sample 2 & $.880[.684 ; 1.076]$ & $-.046[-.262 ; .170]$ & $-.604[-.741 ;-.467]$ & $1>2>3$ \\
\hline Difference Samples 1 vs 2 & Sample $1=2$ & Sample $1=2$ & Sample $1=2$ & \\
\hline \multicolumn{5}{|l|}{ Psychological detachment } \\
\hline Sample 1 & $-.859[-1.082 ;-.636]$ & $-.550[-.728 ;-.372]$ & $.240[.044 ; .436]$ & $3>2>1$ \\
\hline Sample 2 & $-.219[-.415 ;-.023]$ & $.415[.235 ; .595]$ & $.596[.453 ; .739]$ & $3=2>1$ \\
\hline Difference Samples 1 vs 2 & Sample $1<2$ & Sample $1<2$ & Sample $1<2$ & \\
\hline \multicolumn{5}{|c|}{ Counterproductive work behaviors } \\
\hline Sample 1 & $.412[.098 ; .726]$ & $.038[-.064 ; .140]$ & $-.171[-.296 ;-.046]$ & $1>2>3$ \\
\hline Sample 2 & $.509[.205 ; .813]$ & $-.021[-.193 ; .151]$ & $-.382[-.470 ;-.294]$ & $1>2>3$ \\
\hline Difference Samples 1 vs 2 & Sample $1=2$ & Sample $1=2$ & Sample $1>2$ & \\
\hline \multicolumn{5}{|c|}{$\begin{array}{l}\text { Note. CI = 95\% Confidence Interval. Emotional exhaustion, sleeping problems, psychological detachment, and } \\
\text { counterproductive work behaviors are estimated from factor scores with a standard deviation of } 1 \text { and a grand } \\
\text { mean of 0, whereas job satisfaction ( } 1 \text { to } 4) \text { and work performance (0 to 10) are observed scores; Profile } 1: \text { High } \\
\text { Emotional Labor; Profile 2: Moderate Emotional Labor in Sample } 1 \text { and Moderate Surface Acting and High } \\
\text { Deep Acting in Sample 2; Profile 3: Low Emotional Labor in Sample } 1 \text { and Low Surface Acting and Moderately } \\
\text { Low Deep Acting in Sample 2. }\end{array}$} \\
\hline
\end{tabular}




\section{Online Supplemental Materials for: Emotional Labor Profiles: Associations with Key Predictors and Outcomes}

\section{Preliminary Measurement Models}

Preliminary measurement models were estimated using Mplus 8 (Muthén \& Muthén, 2017). Due to the complexity of the multi-sample measurement models underlying all constructs assessed in the present study, these preliminary analyses were conducted separately for the emotional labor variables, the predictors, and the outcomes. These models were estimated as multiple group models, allowing for the estimation of similar models across both samples, and for the progressive integration of invariance constraints to the models. The emotional labor models included, in each sample, three factors for hiding feelings, faking emotions, and deep acting. The predictor model included, in each sample, four factors related to perceived organizational support, perceived supervisor support, perceived colleagues support, and workload. Finally the outcome model included four factors related to emotional exhaustion, sleeping problems, psychological detachment, and counterproductive work behaviors.

The emotional regulation measurement models were estimated using exploratory structural equation modeling (ESEM; Asparouhov \& Muthén, 2009; Marsh, Lüdtke, Trautwein, \& Morin, 2009; Morin, Marsh, \& Nagengast, 2013). The decision to rely on ESEM is based on the results from simulation studies and studies of simulated data (for a review, see Asparouhov, Muthén, \& Morin, 2015) showing that, when assessing conceptually related constructs (Morin, Arens, \& Marsh, 2016), forcing cross-loadings (even as small as .100) present in the population model to be exactly zero according to typical confirmatory factor analytic (CFA) specification forces these cross loadings to be expressed through the inflation of the factor correlations. In contrast, these same studies showed that the free estimation of cross-loadings, even when none are present in the population model, still provides unbiased estimates of the factor correlations. These ESEM factors were specified in a confirmatory manner, using an oblique target rotation (Asparouhov \& Muthén, 2009; Browne, 2001), allowing for the pre-specification of target loadings in a confirmatory manner, while cross-loadings are targeted to be as close to zero as possible, yet still freely estimated. However, because the factors included in the predictors and outcomes models are taken from distinct measurement instruments, these factors were estimated using classical CFA representations. In addition, in the predictors models, five orthogonal method factors were integrated to control for the methodological artefact associated with the parallel wording of the four items used to assess respondents' perceptions of organizational, supervisor, and colleagues support, as well as the negative wording of 6 items (Marsh et al., 2013; Marsh, Scalas, \& Nagengast, 2010; Stinglhamber \& Vandenberghe, 2004). No such control was necessary for the outcomes models.

All of these measurement models were estimated using the robust maximum Likelihood (MLR) estimator. This estimator provides standard errors and tests of fit that are robust in relation to nonnormality and the use of Likert-type rating scales based on five or more response categories (Finney \& DiStephano, 2013). Analyses were conducted using the data from all respondents, using Full Information MLR estimation (FIML; Enders, 2010; Graham, 2009) to account for the limited amount of missing data present at the item level (0\% in Sample 1; 0 to 3.54\% in Sample 2). FIML estimation has been found to result in unbiased parameter estimates under even a very high level of missing data (e.g., 50\%) under Missing At Random (MAR) assumptions, and even in some cases to violations of this assumption (e.g., Enders, 2010; Graham, 2009; Larsen, 2011).

Before saving the factor scores for our main analyses, we verified that the measurement model operated in the same manner across samples, through sequential tests of measurement invariance (Millsap, 2011): (1) configural invariance, (2) weak invariance (loadings), (3) strong invariance (loadings and intercepts), (4) strict invariance (loadings, intercepts, and uniquenesses), (5) invariance of the latent variance-covariance matrix (loadings, intercepts, uniquenesses, and latent variances and covariances), and (6) latent means invariance (loadings, intercepts, uniquenesses, latent variances and covariances, and latent means).

Given the known oversensitivity of the chi-square test of exact fit $\left(\chi^{2}\right)$ to sample size and minor model misspecifications (e.g., Marsh, Hau, \& Grayson, 2005), we relied on goodness-of-fit indices to describe the fit of the models (Hu \& Bentler, 1999): the comparative fit index (CFI), the Tucker-Lewis index (TLI), as well as the root mean square error of approximation (RMSEA) and its $90 \%$ confidence interval. Values greater than .90 for the CFI and TLI indicate adequate model fit, although values 
greater than .95 are preferable. Values smaller than .08 or .06 for the RMSEA respectively support acceptable and excellent model fit. Like the chi-square, chi-square difference tests present a known sensitivity to sample size and minor model misspecifications such that recent studies suggest complementing this information with changes in goodness-of-fit indices (Chen, 2007; Cheung \& Rensvold, 2002) in the context of tests of measurement invariance. An increase of CFI/TLI of .010 or less and an increase in RMSEA of .015 or less between a more restricted model and the preceding one indicate that the invariance hypothesis should not be rejected. Composite reliability coefficients associated with each of the a priori factors are calculated from the model standardized parameters using McDonald (1970) omega ( $\omega)$ coefficient:

$$
\omega=\frac{\left(\sum\left|\lambda_{i}\right|\right)^{2}}{\left[\left(\sum\left|\lambda_{i}\right|\right)^{2}+\sum \delta_{i}\right]}
$$

where $\left|\lambda_{i}\right|$ are the standardized factor loadings associated with a factor in absolute values, and $\delta i$, the item uniquenesses. The numerator, were the factor loadings are summed, and then squared, reflects the proportion of the variance in indicators that reflects true score variance, whereas the denominator reflects the total amount of variance in the items including both true score variance and random measurement errors (reflected by the sum of the items uniquenesses associated with a factor).

The results from these models are reported in supplementary Tables S1, and first support the adequacy of these measurement models (configural models: CFI $\geq .930$; TLI $\geq .900$; RMSEA $\leq .080$ ). In addition, these results support the weak, strong, strict, and latent variance-covariance of the emotional labor and outcome measurement models across samples $(\Delta \mathrm{CFI} \leq .010 ; \Delta \mathrm{TLI} \leq .010$; $\triangle$ RMSEA $\leq .015)$ but not the latent mean invariance of these measurement models. For the predictor model, the results supported the weak invariance of the measurement model across samples, but not its strong measurement invariance. Detailed examination of the parameter estimates associated with the model of weak invariance and of the modification indices associated with the model of strong invariance suggested that this non-invariance was mainly related to the intercepts of three items associated with the workload factor, which tended to be slightly higher in Sample 2. After relaxing the invariance constraints on these items, the results supported this revised model of partial strong invariance, as well as the strict and latent variance-covariance invariance of the predictor measurement model across samples, but not its latent mean invariance. Examination of the latent mean differences revealed that Sample 1 tended to present higher scores on the deep acting (.601 SD units higher than in Sample 1) and psychological detachment (.632 SD units higher than in Sample 1) factors, but lower scores on the workload factor (.676 SD units lower than in Sample 1). Although it was not possible to pursue tests of partial latent mean invariance for the emotional labor model (with ESEM, all latent means need to be similarly constrained or not), models of partial latent means differences in which only the psychological detachment and workload latent means where freely estimated were supported for, respectively, the outcomes and predictors models.

To ensure that the latent profiles estimated were based on fully comparable measures across samples, the factor scores used in the main analyses were saved from the most invariant model. Although only strict invariance is required to ensure the comparability of factors scores across groups, there are advantages to saving factor scores from a model of latent variance-covariance or latent mean invariance (Meyer \& Morin, 2016; Morin, 2016). More precisely, saving factor scores based on a measurement model in which the variances are equivalent across groups and constrained to take a value of 1 provides scores that can be readily interpreted in standard deviation units. Furthermore, saving factor scores based on a measurement model in which the means are equivalent across groups and constrained to take a value of 0 provides scores that can be readily interpreted as deviations from a grand mean of 0 . In the present study, variables associated with a non-invariant latent mean were estimated in each sample as deviations around a grand mean of 0 . Invariant parameter estimates for the emotional labor, predictor, and outcome models are respectively reported in Tables S2, S3, and S4. Generally, all factors were well-defined through high factor loadings, resulting in fully acceptable model-based composite reliability coefficients, ranging from $\omega=.701$ to .917 . 


\section{Latent Profile Analyses: Technical Considerations}

For each sample, we examined solutions including 1 to 8 latent profiles in which the means of the emotional labor factors were freely estimated in all profiles. Despite the advantages of relying on models in which the indicators' variances are also freely estimated in all profiles (Diallo, Morin, \& Lu, 2016), these alternative models tended to converge on improper solutions (e.g., negative variance estimates, non-positive definite Fisher Information matrix) or not converge at all in the present research. This suggests the inadequacy of these models and their overparameterization, and the superiority of our more parsimonious models (Chen, Bollen, Paxton, Curran, \& Kirby, 2001).

Statistical indices are available to support the decision To determine the optimal number of profiles in the data (McLachlan \& Peel, 2000): (i) The Akaïke Information Criterion (AIC), (ii) the Consistent AIC (CAIC), (iii) the Bayesian Information Criterion (BIC), (iv) the sample-size Adjusted BIC (ABIC), (v) the standard and adjusted Lo, Mendel and Rubin's (2001) Likelihood Ratio Tests (LMR/aLMR; because these two tests typically yield the same conclusion, we report only the aLMR), and (vi) the Bootstrap Likelihood Ratio Test (BLRT). A lower AIC, CAIC, BIC and ABIC value suggests a better-fitting model. The aLMR and BLRT compare a k class model with a k-1 class model. A significant $\mathrm{p}$ value indicates that the $\mathrm{k}-1$ class model should be rejected in favor of a $\mathrm{k}$ class model. Simulation studies indicate that four of these indicators (CAIC, BIC, ABIC, and BLRT) are particularly effective, while the AIC and LMR/aLMR should not be used in the class enumeration process as they respectively tend to over- and under- extract incorrect number of profiles (e.g., Diallo, Morin, \& Lu, 2016, 2017). These indicators are thus reported in order to ensure a complete disclosure and to allow for comparisons with previous profile analyses reported in the literature, but are not used to select the optimal number of profiles. It should be noted that these tests remain heavily influenced by sample size (Marsh, Lüdtke, Trautwein, \& Morin, 2009), so that with sufficiently large samples, they may keep on suggesting the addition of profiles without reaching a minimum. In these cases, information criteria should be graphically presented through "elbow plots" illustrating the gains associated with additional profiles (Morin, 2016; Morin et al., 2011). In these plots, the point after which the slope flattens suggests the optimal number of profiles. Finally, the entropy indicates the precision with which the cases are classified into the various profiles. The entropy should not be used to determine the optimal number of profiles (Lubke \& Muthén, 2005), but it provides a useful summary of the classification accuracy ( 0 to 1$)$, with higher values indicating more accuracy.

The tests of profile similarity followed the sequential strategy proposed by Morin, Meyer, Creusier, and Biétry (2016). The first step examines whether the same number of profiles can be identified in each sample (i.e., configural similarity) and corresponds to the previously described sample-specific LPA. A multi-group LPA can then be estimated from a model of configural similarity, to which equality constraints are progressively integrated. In the second step, the structural similarity of the profiles is verified by including equality constraints across samples on the means of the profile indicators (i.e., the emotional labor factors) to test whether the profiles retain the same shape across samples. If this form of similarity holds, then the third step tests the dispersion similarity of the profiles. In this step, we include equality constraints across samples on the variances of the profile indicators to verify whether the within-profile variability remains comparable across samples. Fourth, starting from the most similar model from the previous sequence, the distributional similarity of the profiles is tested by constraining the class probabilities to equality across samples to ascertain whether the relative size of the profiles remains the same. The fit of these models can be compared using the aforementioned information criteria, and Morin, Meyer et al. (2016) suggest that at least two indices out of the CAIC, BIC, and ABIC should be lower for the more "similar" model to support the hypothesis of profile similarity. 


\section{Latent Profile Analyses: Selection of the Optimal Solution}

The fit indices associated with the LPA estimated separately in each sample and across samples are reported in Table S5 of these online supplements. With the exception of the CAIC which supported the 6-profile solution in Sample 2, all other indicators kept on suggesting the addition of profiles to the solution, without ever reaching a minimum. To complement this information, we thus relied on the examination of graphical elbow plots (see Figures S1 and S2 in these online supplements). These plots show that the improvement in fit flattened out at 3 profiles in Sample 1, and between 3 and 4 profiles in Sample 2. The examination of the 3-profile solution, and of the adjacent 2and 4- profile solutions showed that these solutions were all fully proper statistically in both samples. This examination also revealed moving from a 2- to 3-profile solution resulted in the addition of a well-defined, qualitatively distinct, and theoretically meaningful profile to the solution in both samples. However, moving from the 3- to the 4-profile solution simply resulted in the division of one of the existing profile into two profiles differing only quantitatively from one another. Even more importantly, all of these solutions revealed a high level of similarity across samples. The 3-profile solution was thus retained in each sample, supporting the configural similarity of this solution.

A multi-group LPA of configural similarity, including 3-profiles per sample, was then estimated. This model was contrasted with a model of structural similarity by constraining the within-profile means on the three emotional labor factors to be equal across samples. This second model resulted in higher values on all information criteria, thereby failing to support the structural similarity of the profiles across samples, which was surprising given the high level of similarity observed in a visual comparison of the sample-specific solutions. However, a careful examination revealed that scores on the deep acting indicator were substantially higher in Sample 2 within two of the profiles, which is consistent with our observation of latent mean differences on this indicator across samples in the context of our preliminary analyses. We thus estimated an additional model of partial structural similarity in which equality constraints across samples where only relaxed for deep acting in two of the profiles. Relative to the model of configural similarity, this model resulted in lower values on the CAIC and BIC, thereby supporting the partial structural similarity of this solution across samples. This model was then contrasted to a model of dispersion similarity in which the within-profile variance of the emotional labor factors was constrained to be equal across samples. Compared to the model of partial structural similarity, this model resulted in a lower value on the CAIC and BIC, thus supporting the dispersion similarity of the solution. Finally, we estimated a model of distributional similarity by constraining the size of the latent profiles to be equal across samples. Compared with the model of dispersion similarity, this model resulted in higher values on all indicators, thereby failing to support the distributional similarity of the solution. The model of dispersion similarity was retained for interpretation and is described in the main manuscript.

Predictors of profile membership were added to the final model of dispersion similarity. We first examined a model in which the associations between the predictors and the probability of profile membership was freely estimated across samples, and contrasted this model with one in which these relations were constrained to equality across samples. The model of predictive similarity resulted in lower values for the CAIC, BIC, and ABIC and was thus retained for interpretation.

The outcomes were also integrated to the final model of dispersion similarity described earlier. We first estimated models in which the within-profile levels of these outcomes were freely estimated across samples, and contrasted these models with models in which these levels were constrained to be equal across samples (i.e., explanatory similarity). As shown in Table S5, the model of explanatory similarity resulted in higher values on the AIC, BIC, and ABIC and was thus rejected, suggesting that the relations between profile membership and the outcome variables differ across profiles. 


\section{References used in the supplements}

Asparouhov, T., \& Muthén, B.O. (2009). Exploratory structural equation modeling. Structural Equation Modeling, 16, 397-438.

Asparouhov, T., Muthén, B., \& Morin, A.J.S. (2015). Bayesian structural equation modeling with cross-loadings and residual covariances. Journal of Management, 41, 1561-1577.

Browne, M.W. (2001). An overview of analytic rotation in exploratory factor analysis. Multivariate Behavioral Research, 36, 111-150.

Chen, F.F. (2007). Sensitivity of goodness of fit indexes to lack of measurement. Structural Equation Modeling, 14, 464-504.

Chen, F., Bollen, K.A., Paxton, P., Curran, P.J., \& Kirby, J.B. (2001). Improper solutions in structural models: Causes, consequences, and strategies. Sociological Methods \& Research, 29, 468-508.

Cheung, G.W., \& Rensvold,R. B. (2002). Evaluating goodness-of fit indexes for testing measurement invariance. Structural Equation Modeling, 9, 233-255.

Diallo, T.M.O, Morin, A.J.S., \& Lu, H. (2016). Impact of misspecifications of the latent variancecovariance and residual matrices on the class enumeration accuracy of growth mixture models. Structural Equation Modeling, 23, 507-531.

Diallo, T.M.O., Morin, A.J.S., \& Lu, H. (2017). The impact of total and partial inclusion or exclusion of active and inactive time invariant covariates in growth mixture. Psychological Methods, 22, $166-190$.

Enders, C.K. (2010). Applied missing data analysis. New York, NY: Guilford.

Finney, S.J., \& DiStefano, C. (2013). Non-normal and categorical data in structural equation modeling. In G.R. Hancock \& R.O. Mueller (Eds), Structural equation modeling: A second course, $2^{\text {nd }}$ edition (pp. 439-492). Charlotte, NC: IAP.

Graham, J.W. (2009). Missing data analysis: Making it work in the real world. Annual Review of Psychology, 60, 549-576.

Hu, L.-T., \& Bentler, P.M. (1999). Cutoff criteria for fit indexes in covariance structure analysis: Conventional criteria versus new alternatives. Structural Equation Modeling, 6, 1-55.

Larsen, R. (2011). Missing data imputation versus full information maximum likelihood with second level dependencies. Structural Equation Modeling, 18, 649-662.

Lo, Y., Mendell, N., \& Rubin, D. (2001). Testing the number of components in a normal mixture. Biometrika, 88, 767-778.

Lubke, G.H., \& Muthén, B.O. (2005). Investigating population heterogeneity with factor mixture models. Psychological Methods, 10, 21-39.

Marsh, H.W., Abduljabbar, A.S., Abu-Hilal, M., Morin, A.J.S., Abdelfattah, F., Leung, K.C., Xu, M.K., Nagengast, B., \& Parker, P. (2013). Factor structure, discriminant and convergent validity of TIMSS math and science motivation measures: A comparison of USA and Saudi Arabia. Journal of Educational Psychology, 105, 108-128.

Marsh, H.W., Hau, K., \& Grayson, D. (2005). Goodness of fit in structural equation models. In A. Maydeu-Olivares \& J.J. McArdle (Eds.), Contemporary psychometrics: A festschrift for Roderick P. McDonald (pp. 275-340). Mahwah, NJ: Erlbaum.

Marsh, H.W., Lüdtke, O., Trautwein, U., \& Morin, A.J.S. (2009). Latent profile analysis of academic self-concept dimensions: Synergy of person- and variable-centered approaches to the internal/external frame of reference model. Structural Equation Modeling, 16, 1-35.

Marsh, H.W., Scalas, L.F., \& Nagengast, B. (2010). Longitudinal tests of competing factor structures for the Rosenberg self-esteem scale: Traits, ephemeral artifacts, and stable response styles. Psychological Assessment, 22, 366-381.

McLachlan, G., \& Peel, D. (2000). Finite mixture models. New York, NY: Wiley.

Meyer, J.P., \& Morin, A.J.S. (2016). A person-centered approach to commitment research: Theory, research, and methodology. Journal of Organizational Behavior, 37, 584-612.

Morin, A.J.S. (2016). Person-centered research strategies in commitment research. In J.P. Meyer (Ed.), The handbook of employee commitment (pp. 490-508). Cheltenham, UK: Edward Elgar.

Morin, A.J.S., Arens, A.K., \& Marsh, H.W. (2016). A bifactor exploratory structural equation modeling framework for the identification of distinct sources of construct-relevant psychometric multidimensionality. Structural Equation Modeling, 23, 116-139.

Morin, A.J.S., Maïano, C., Nagengast, B., Marsh, H.W., Morizot, J., \& Janosz, M. (2011). Growth 
mixture modeling of adolescents' trajectories of anxiety: The impact of untested invariance assumptions on substantive interpretations. Structural Equation Modeling, 18, 613-648.

Morin, A.J.S., Marsh, H.W., \& Nagengast, B. (2013). Chapter 10. Exploratory structural equation modeling. In G.R. Hancock \& R.O. Mueller (Eds), Structural equation modeling: A second course, $2^{\text {nd }}$ edition (pp. 395-436). Charlotte, NC: IAP.

Morin, A.J.S., Meyer, J.P., Creusier, J., \& Biétry, F. (2016). Multiple-group analysis of similarity in latent profile solutions. Organizational Research Methods, 19, 231-254.

McDonald, R.P. (1970). Theoretical foundations of principal factor analysis, canonical factor analysis, and alpha factor analysis. British Journal of Mathematical \& Statistical Psychology, 23, 1-21.

Millsap, R.E. (2011). Statistical approaches to measurement invariance. New York, NY: Taylor \& Francis.

Muthén, L. K., \& Muthén, B. O. (2017). Mplus user's guide. Los Angeles, CA: Muthén \& Muthén.

Stinglhamber, F., \& Vandenberghe, C. (2003) Organizations and supervisors as sources of support and targets of commitment. Journal of Organizational Behavior, 24, 251-270. 


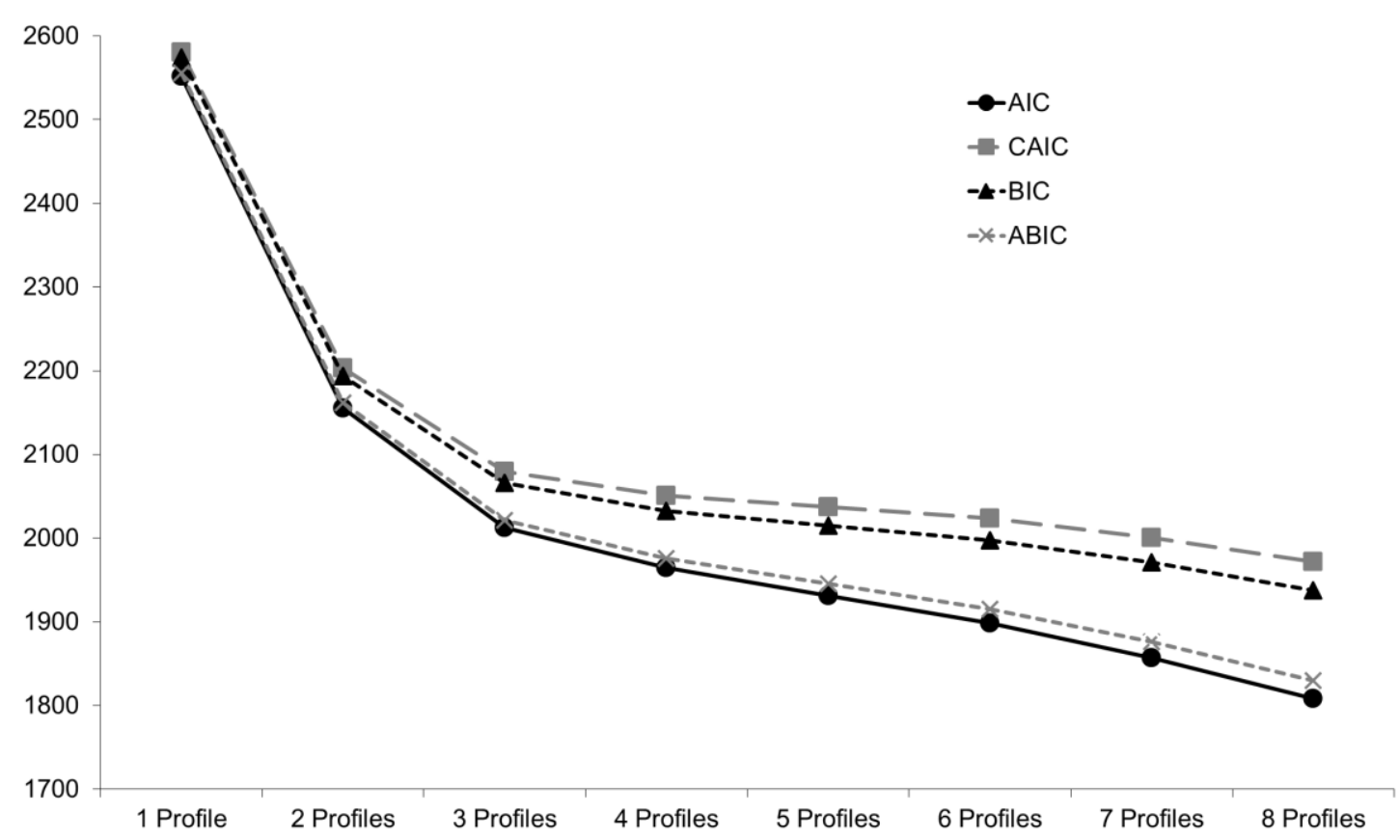

\section{Figure S1}

Elbow Plot of the Value of the Information Criteria for Solutions Including Different Numbers of Latent Profiles (Sample 1)

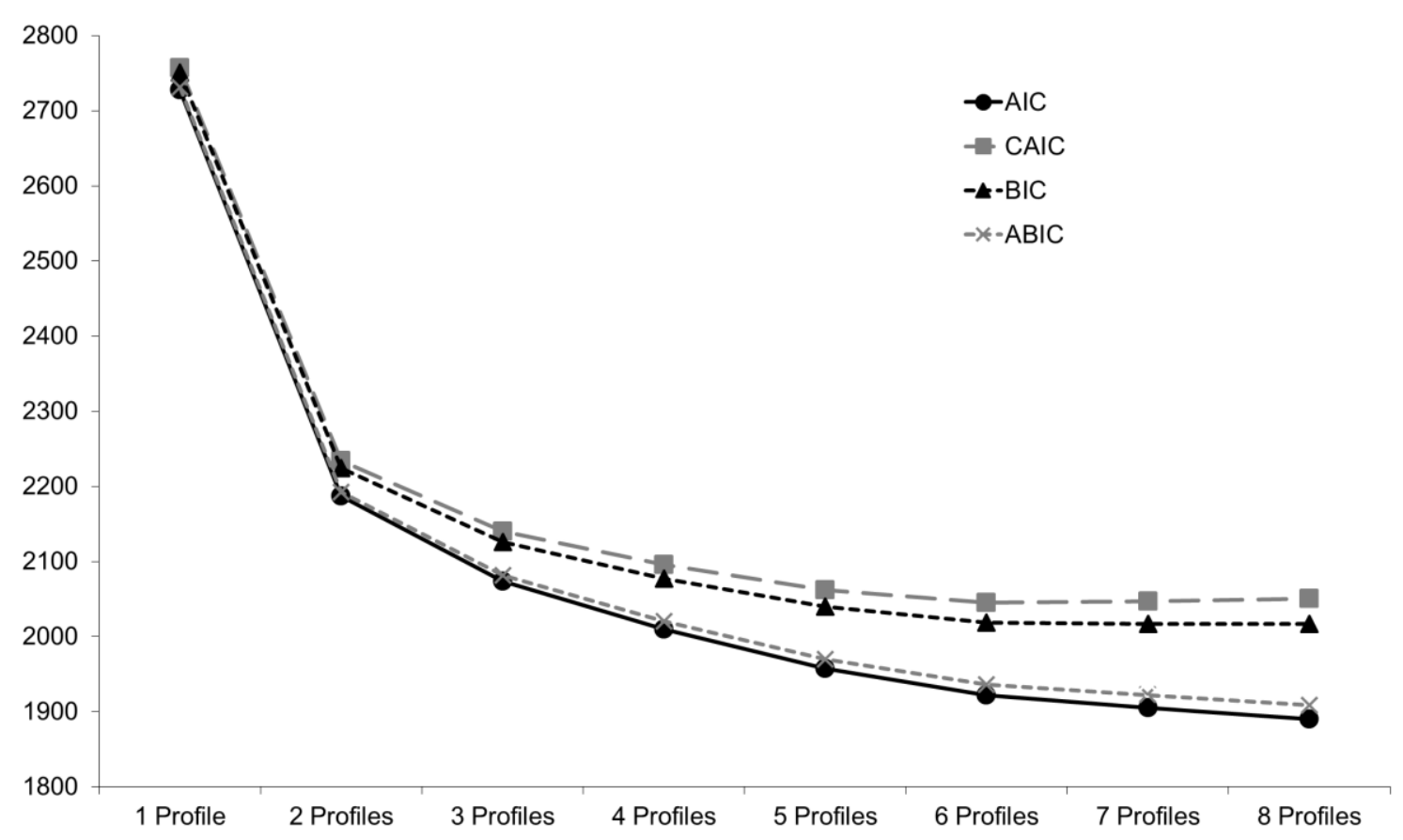

\section{Figure S2}

Elbow Plot of the Value of the Information Criteria for Solutions Including Different Numbers of Latent Profiles (Sample 2) 
Table S1

Goodness-of-Fit Statistics of the Preliminary Measurement Models

\begin{tabular}{|c|c|c|c|c|c|c|c|c|c|}
\hline Description & $\chi^{2}(d f)$ & CFI & TLI & RMSEA & $90 \% \mathrm{CI}$ & $\Delta \chi^{2}(d f)$ & $\Delta \mathrm{CFI}$ & $\Delta \mathrm{TLI}$ & $\Delta$ RMSEA \\
\hline \multicolumn{10}{|l|}{ Emotional Labor Measurement Models } \\
\hline Configural invariance & $73.828(24) *$ & .985 & .955 & .080 & {$[.060 ; .102]$} & - & - & - & - \\
\hline Weak invariance & $79.545(42)$ & .989 & .981 & .053 & {$[.035 ; .070]$} & $15.231(18)$ & +.004 & +.026 & -.027 \\
\hline Strong invariance & $98.647(48)^{*}$ & .985 & .977 & .057 & {$[.041 ; .073]$} & $20.423(6)^{*}$ & -.004 & -.004 & +.004 \\
\hline Strict invariance & $135.664(57)^{*}$ & .976 & .970 & .066 & {$[.051 ; .080]$} & $34.691(9)^{*}$ & -.009 & -.007 & +.009 \\
\hline Latent variance-covariance invariance & $156.365(63)^{*}$ & .972 & .968 & .068 & {$[.055 ; .081]$} & $21.522(6)^{*}$ & -.004 & -.002 & -.001 \\
\hline Latent means invariance & $225.368(66)^{*}$ & .952 & .948 & .087 & {$[.074 ; .099]$} & $82.968(3) *$ & -.020 & -.020 & +.019 \\
\hline \multicolumn{10}{|l|}{ Predictor Measurement Models } \\
\hline Configural invariance & $436.870(180)^{*}$ & .935 & .902 & .067 & {$[.059 ; .075]$} & - & - & - & - \\
\hline Weak invariance & $486.148(206)^{*}$ & .929 & .907 & .065 & {$[.058 ; .073]$} & $49.206(26)^{*}$ & -.006 & +.005 & -.002 \\
\hline Strong invariance & $716.616(214)^{*}$ & .873 & .839 & .086 & {$[.079 ; .092]$} & $243.379(8) *$ & -.056 & -.068 & +.021 \\
\hline Partial strong invariance & $490.282(211)^{*}$ & .930 & .909 & .064 & {$[.057 ; .072]$} & $3.352(5)$ & +.001 & +.002 & -.001 \\
\hline Strict invariance & $528.410(228)^{*}$ & .924 & .910 & .064 & {$[.057 ; .071]$} & $38.459(17)^{*}$ & -.006 & +.001 & .000 \\
\hline Latent variance-covariance invariance & $552.175(243)^{*}$ & .920 & .913 & .063 & {$[.056 ; .070]$} & $27.393(15)$ & -.004 & +.003 & -.001 \\
\hline Latent means invariance & $644.088(252)^{*}$ & .901 & .893 & .070 & {$[.063 ; .076]$} & $97.189(9)^{*}$ & -.019 & -.020 & +.007 \\
\hline Partial latent means invariance & $606.109(251)^{*}$ & .911 & .903 & .066 & {$[.060 ; .073]$} & $60.408(8) *$ & -.009 & -.010 & +.003 \\
\hline \multicolumn{10}{|l|}{ Outcome Measurement Models } \\
\hline Configural invariance & $608.360(258)^{*}$ & .932 & .919 & .065 & {$[.058 ; .072]$} & - & - & - & - \\
\hline Weak invariance & $638.088(272)^{*}$ & .929 & .920 & .065 & {$[.058 ; .071]$} & $30.730(14)^{*}$ & -.003 & +.001 & .000 \\
\hline Strong invariance & $701.903(286)^{*}$ & .920 & .913 & .067 & {$[.061 ; .074]$} & $67.196(14)^{*}$ & -.009 & -.007 & +.002 \\
\hline Strict invariance & $755.361(304)^{*}$ & .912 & .911 & .068 & {$[.062 ; .074]$} & $48.745(18)^{*}$ & -.008 & -.002 & +.001 \\
\hline Latent variance-covariance invariance & $780.299(314)^{*}$ & .909 & .911 & .068 & {$[.062 ; .074]$} & $24.904(10)^{*}$ & -.003 & .000 & .000 \\
\hline Latent means invariance & $840.968(318) *$ & .898 & .902 & .072 & {$[.066 ; .077]$} & $67.963(4) *$ & -.011 & -.009 & +.004 \\
\hline Partial latent means invariance & $782.286(317)^{*}$ & .909 & .912 & .068 & {$[.062 ; .074]$} & $1.369(3)$ & .000 & +.001 & .000 \\
\hline
\end{tabular}

Note. $* p<.01 ; \chi^{2}$ : robust chi-square test of exact fit; $d f$ : degrees of freedom; CFI: comparative fit index; TLI: Tucker-Lewis index; RMSEA: root mean square error of approximation; $90 \%$ CI: $90 \%$ confidence interval; $\Delta \chi^{2}$ : scaled chi-square difference tests. 
Table S2

Invariant Standardized Factor Loadings $(\lambda)$ and Uniquenesses $(\delta)$ for the Emotional Labor Model

\begin{tabular}{ccccc}
\hline & Factor 2 & Factor 2 & Factor 3 & \\
Items & $\lambda$ & $\lambda$ & $\lambda$ & $\delta$ \\
\hline 1. Hiding & & & & \\
Item 1 & $\mathbf{. 6 0 9}$ & .252 & -.004 & .346 \\
Item 2 & $\mathbf{. 8 9 7}$ & .053 & -.028 & .158 \\
Item 3 & $\mathbf{. 9 7 3}$ & -.072 & -.022 & .176 \\
2. Faking & & & & \\
Item 1 & .086 & $\mathbf{. 9 5 1}$ & -.118 & .125 \\
Item 2 & .056 & $\mathbf{. 5 5 5}$ & .328 & .258 \\
Item 3 & .319 & $\mathbf{. 2 4 3}$ & .405 & .254 \\
3. Deep Acting & & & & \\
Item 1 & .017 & .439 & $\mathbf{. 4 2 3}$ & .348 \\
Item 2 & -.075 & .102 & $\mathbf{. 8 6 6}$ & .207 \\
Item 3 & .167 & -.066 & $\mathbf{. 7 1 0}$ & .389 \\
$\omega$ & .900 & .828 & .809 & \\
\hline
\end{tabular}

Note. $\lambda$ : factor loading (bold: target factor loadings); $\delta$ : item uniqueness; $\omega$ : omega coefficient of model-based composite reliability.

Table S3

Invariant Standardized Factor Loadings $(\lambda)$ and Uniquenesses $(\delta)$ for the Predictors Model

\begin{tabular}{|c|c|c|c|c|c|}
\hline Items & $\begin{array}{c}\text { Factor } 1 \\
\lambda\end{array}$ & $\begin{array}{c}\text { Factor } 2 \\
\lambda\end{array}$ & $\begin{array}{c}\text { Factor } 3 \\
\lambda \\
\end{array}$ & $\begin{array}{c}\text { Factor } 4 \\
\lambda\end{array}$ & $\delta$ \\
\hline \multicolumn{6}{|c|}{ 1. Perceived Organizational Support } \\
\hline Item 1 & .874 & & & & .196 \\
\hline Item 2 & .532 & & & & .371 \\
\hline Item 3 & .765 & & & & .287 \\
\hline Item 4 & .523 & & & & .207 \\
\hline \multicolumn{6}{|c|}{ 2. Perceived Supervisor Support } \\
\hline Item 1 & & .873 & & & .237 \\
\hline Item 2 & & 615 & & & .347 \\
\hline Item 3 & & .852 & & & .259 \\
\hline Item 4 & & 627 & & & .380 \\
\hline \multicolumn{6}{|c|}{ 3. Perceived Colleagues Support } \\
\hline Item 1 & & & .874 & & .235 \\
\hline Item 2 & & & .470 & & .545 \\
\hline Item 3 & & & .796 & & .351 \\
\hline Item 4 & & & .586 & & .390 \\
\hline \multicolumn{6}{|l|}{ 4. Workload } \\
\hline Item 1 & & & & 694 & .518 \\
\hline Item 2 & & & & .750 & .438 \\
\hline Item 3 & & & & .787 & .380 \\
\hline Item 4 & & & & 695 & .517 \\
\hline Item 5 & & & & 642 & .588 \\
\hline$\omega$ & .872 & .878 & .830 & .839 & \\
\hline
\end{tabular}

Note. $\lambda$ : factor loading; $\delta$ : item uniqueness; $\omega$ : omega coefficient of model-based composite reliability. 
Table S4

Invariant Standardized Factor Loadings $(\lambda)$ and Uniquenesses $(\delta)$ for the Outcomes Model

\begin{tabular}{|c|c|c|c|c|c|}
\hline Items & $\begin{array}{c}\text { Factor } 1 \\
\lambda\end{array}$ & $\begin{array}{c}\text { Factor } 2 \\
\lambda\end{array}$ & $\begin{array}{c}\text { Factor } 3 \\
\lambda\end{array}$ & $\begin{array}{c}\text { Factor } 4 \\
\lambda\end{array}$ & $\delta$ \\
\hline \multicolumn{6}{|l|}{ 1. Emotional exhaustion } \\
\hline Item 1 & .792 & & & & .372 \\
\hline Item 2 & .724 & & & & .476 \\
\hline Item 3 & .834 & & & & .304 \\
\hline Item 4 & 866 & & & & .251 \\
\hline Item 5 & .617 & & & & .620 \\
\hline \multicolumn{6}{|l|}{ 2. Sleeping problems } \\
\hline Item 1 & & .757 & & & .427 \\
\hline Item 2 & & .840 & & & .294 \\
\hline Item 3 & & 871 & & & .241 \\
\hline Item 4 & & .756 & & & .429 \\
\hline \multicolumn{6}{|c|}{ 3. Psychological detachment } \\
\hline Item 1 & & & .933 & & .129 \\
\hline Item 2 & & & 915 & & .162 \\
\hline Item 3 & & & .750 & & .438 \\
\hline Item 4 & & & .818 & & .331 \\
\hline \multicolumn{6}{|c|}{ 4. Counterproductive work behaviors } \\
\hline Item 1 & & & & .604 & .636 \\
\hline Item 2 & & & & .510 & .740 \\
\hline Item 3 & & & & .458 & .790 \\
\hline Item 4 & & & & .696 & .516 \\
\hline Item 5 & & & & .550 & .698 \\
\hline$\omega$ & .879 & .882 & 917 & .701 & \\
\hline
\end{tabular}

Note. $\lambda$ : factor loading; $\delta$ : item uniqueness; $\omega$ : omega coefficient of model-based composite reliability. 
Table S5

Results from the Latent Profiles Analyses across Samples

\begin{tabular}{|c|c|c|c|c|c|c|c|c|}
\hline Model & LL & $\# \mathrm{fp}$ & Scaling & AIC & CAIC & $\mathrm{BIC}$ & $\mathrm{ABIC}$ & Entropy \\
\hline \multicolumn{9}{|l|}{ Sample 1} \\
\hline 1 Profile & -1269.825 & 6 & .817 & 2551.650 & 2580.462 & 2574.462 & 2555.430 & $\mathrm{Na}$ \\
\hline 2 Profiles & -1067.632 & 10 & 1.316 & 2155.264 & 2203.286 & 2193.286 & 2161.565 & .828 \\
\hline 3 Profiles & -992.224 & 14 & 1.055 & 2012.448 & 2079.678 & 2065.678 & 2021.269 & .836 \\
\hline 4 Profiles & -964.175 & 18 & 1.026 & 1964.351 & 2050.789 & 2032.789 & 1975.692 & .838 \\
\hline 5 Profiles & -943.735 & 22 & 1.188 & 1931.470 & 2037.116 & 2015.116 & 1945.332 & .875 \\
\hline 6 Profiles & -923.321 & 26 & 1.219 & 1898.642 & 2023.497 & 1997.497 & 1915.024 & .869 \\
\hline 7 Profiles & -898.439 & 30 & 1.153 & 1856.878 & 2000.942 & 1970.942 & 1875.781 & .941 \\
\hline 8 Profiles & -870.301 & 34 & 1.207 & 1808.602 & 1971.874 & 1937.874 & 1830.025 & .940 \\
\hline \multicolumn{9}{|l|}{ Sample 2} \\
\hline 1 Profile & -1358.024 & 6 & .751 & 2728.048 & 2756.487 & 2750.487 & 2731.457 & $\mathrm{Na}$ \\
\hline 2 Profiles & -1083.407 & 10 & 1.001 & 2186.814 & 2234.211 & 2224.211 & 2192.495 & .918 \\
\hline 3 Profiles & -1022.828 & 14 & 1.137 & 2073.655 & 2140.012 & 2126.012 & 2081.609 & .849 \\
\hline 4 Profiles & -987.011 & 18 & 1.302 & 2010.021 & 2095.338 & 2077.338 & 2020.248 & .830 \\
\hline 5 Profiles & -956.803 & 22 & 1.031 & 1957.607 & 2061.882 & 2039.882 & 1970.106 & .861 \\
\hline 6 Profiles & -934.897 & 26 & 1.063 & 1921.794 & 2045.028 & 2019.028 & 1936.566 & .885 \\
\hline 7 Profiles & -922.504 & 30 & 1.126 & 1905.008 & 2047.202 & 2017.202 & 1922.053 & .902 \\
\hline 8 Profiles & -910.829 & 34 & 1.196 & 1889.657 & 2050.810 & 2016.810 & 1908.975 & 912 \\
\hline \multicolumn{9}{|l|}{ Tests of Profile Similarity across Samples } \\
\hline Configural Similarity & -2459.741 & 29 & 1.0926 & 4977.481 & 5135.954 & 5106.954 & 5014.881 & .903 \\
\hline Structural Similarity & -2528.746 & 20 & 1.0822 & 5097.491 & 5206.783 & 5186.783 & 5123.284 & .894 \\
\hline Partial Structural Similarity & -2477.546 & 22 & 1.0200 & 4999.092 & 5119.313 & 5097.313 & 5027.464 & .907 \\
\hline Dispersion Similarity & -2483.111 & 19 & 1.0576 & 5004.223 & 5108.050 & 5089.050 & 5028.726 & .906 \\
\hline Distributional Similarity & -2492.295 & 17 & 1.0559 & 5018.590 & 5111.488 & 5094.488 & 5040.514 & .906 \\
\hline \multicolumn{9}{|l|}{ Predictive Similarity } \\
\hline Relations between predictors and profiles freely estimated & -2404.037 & 29 & 1.0100 & 4866.074 & 5024.547 & 4995.547 & 4903.474 & .912 \\
\hline Relations between predictors and profiles invariant & -2416.325 & 17 & 1.0021 & 4866.650 & 4959.548 & 4942.548 & 4888.574 & .912 \\
\hline \multicolumn{9}{|l|}{ Explanatory Similarity } \\
\hline Relations between profiles and outcomes freely estimated & -7540.214 & 47 & 1.2012 & 15174.429 & 15431.265 & 15384.265 & 15235.042 & .924 \\
\hline Relations between profiles and outcomes invariant & -7602.560 & 29 & 1.2515 & 15263.121 & 15421.594 & 15392.594 & 15300.520 & .922 \\
\hline
\end{tabular}

Note. LL: Model LogLikelihood; \#fp: Number of free parameters; Scaling: Scaling correction factor; AIC: Akaïke Information Criteria; CAIC: Constant AIC; BIC: Bayesian Information Criteria; ABIC: Sample-Size adjusted BIC. 
Table S6

Detailed Results from the Final Multi-Sample Latent Profile Solution (Distributional Similarity)

\begin{tabular}{|c|c|c|c|c|c|c|}
\hline & $\begin{array}{c}\text { Profile } 1 \\
\text { Mean }[\mathrm{CI}]\end{array}$ & $\begin{array}{c}\text { Profile } 2 \text { (Sample 1) } \\
\text { Mean [CI] }\end{array}$ & $\begin{array}{c}\text { Profile } 2 \text { (Sample 2) } \\
\text { Mean [CI] }\end{array}$ & $\begin{array}{c}\text { Profile } 3 \text { (Sample 1) } \\
\text { Mean [CI] }\end{array}$ & $\begin{array}{c}\text { Profile } 3 \text { (Sample 2) } \\
\text { Mean [CI] }\end{array}$ & Variance $[\mathrm{CI}]$ \\
\hline Faking emotions & $1.338[1.229 ; 1.446]$ & $.251[.138 ; .363]$ & Identical & $-.873[-.949 ;-.797]$ & Identical & $.204[.177 ; .231]$ \\
\hline Hiding feelings & $1.104[1.004 ; 1.203]$ & $.250[.139 ; .360]$ & Identical & $-.903[-1.010 ;-.795]$ & Identical & $.318[.276 ; .361]$ \\
\hline Deep acting & $1.559[1.428 ; 1.690]$ & $.104[-.029 ; .238]$ & $.848[.702 ; .994]$ & $-.729[-.810 ;-.647]$ & $-.286[-.403 ;-.168]$ & $.304[.267 ; .342]$ \\
\hline
\end{tabular}

Note. $\mathrm{CI}=95 \%$ Confidence Interval. The profile indicators are estimated from factor scores with a standard deviation of 1 and a grand mean of 0 Profile 1 :

High Emotional Labor; Profile 2: Moderate Emotional Labor in Sample 1 and Moderate Surface Acting and High Deep Acting in Sample 2; Profile 3: Low

Emotional Labor in Sample 1 and Low Surface Acting and Moderately Low Deep Acting in Sample 2.

Table S7

Posterior Classification Probabilities for Most Likely Latent Profile Membership (Row) by Latent Profile (Column)

\begin{tabular}{llll}
\hline Profiles & Profile 1 & Profile 2 & Profile 3 \\
\hline Sample 1 & & & \\
1 & .949 & .051 & 0 \\
2 & .019 & .923 & .058 \\
3 & 0 & .063 & .937 \\
\hline Sample 2 & & & \\
1 & .932 & .068 & 0 \\
2 & .070 & .895 & .035 \\
3 & 0 & .037 & .963 \\
\hline
\end{tabular}

Note. Profile 1: High Emotional Labor; Profile 2: Moderate Emotional Labor in Sample 1 and Moderate Surface Acting and High Deep Acting in Sample 2; Profile 3: Low Emotional Labor in Sample 1 and Low Surface Acting and Moderately Low Deep Acting in Sample 2. 